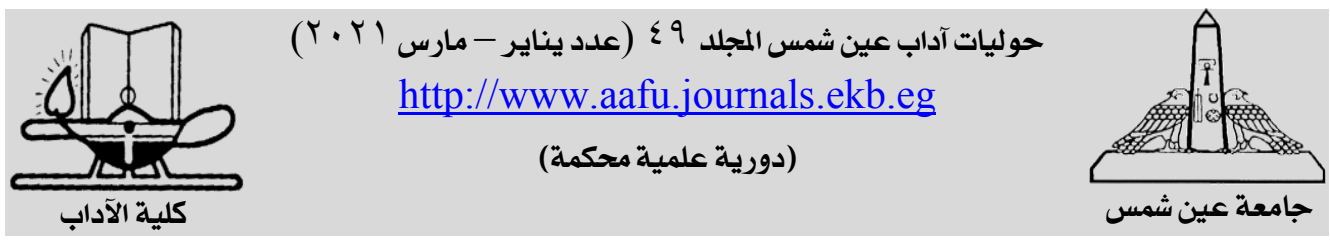

\title{
البناء الصوري الشاهد الأحلام الفنتازية في السينما الرقمية
}

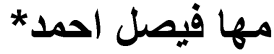 \\ قسم الدراما ـ كلية الفنون الجميلة- جامعة بغدادــ العراق \\ mahaalias2020@gmail.com
}

تمثل الاحلام مادة سينمائية بامتياز يتداخل وسطها الواقع والخيال، وتصبح بنية

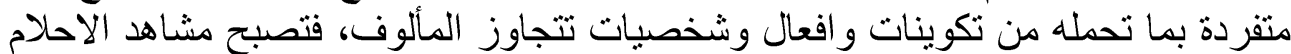

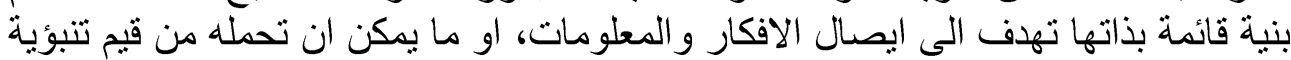

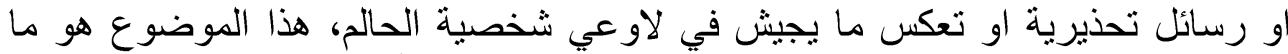

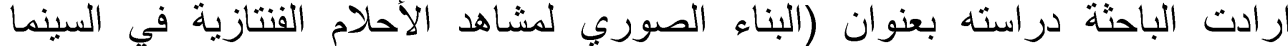
الرقمية). اعتمد البحث على اساس تنظير ارتكز على اربعة فصول جاءت على النحو

الفصل الاول (الاطار المنهج): تضمن هذا الفصل مشكلة البحث التي تحدد بالتساؤل الآتي: ما الكيفية التي يتم بها البناء الصوري لمشاهد الاحلام الفنتازية في السينما الرقمية؛

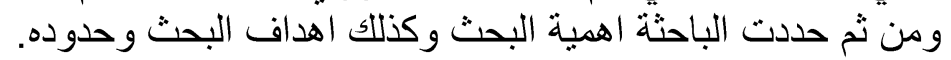

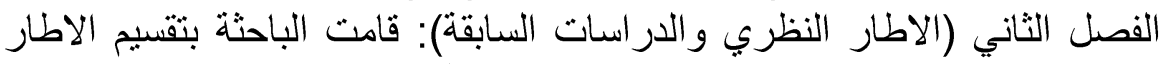

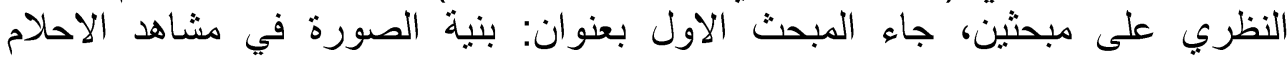

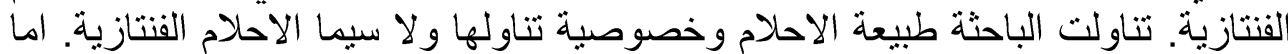

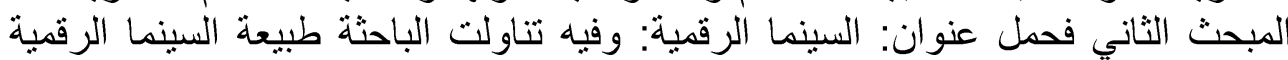

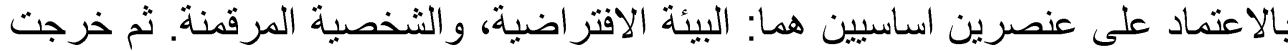
الباحثة بمؤشرات الاطار النظري. وختمت الفصل بالدر اسات السابقة.

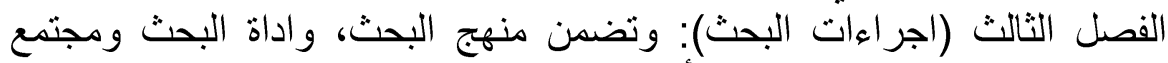
البحث، ووحدة التحليل وعينة البحث، وأخيراً تحليل العينة التي كانت التئ الفيلم السينمائي (الوحش الذي ينادي 7 (• ب)، من اخر اج: (JA Bayona).

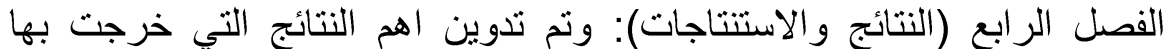

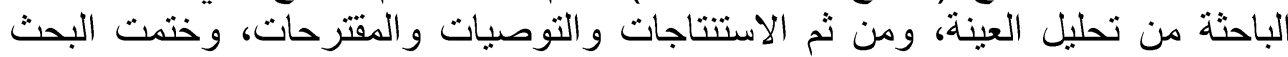

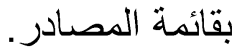




\section{القصل الاول

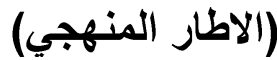

أولاً: مشكلة البحث

بفضل تطور التقنية والعناصر اللغوية التي تمتلك قدرة التعبير والتجسيد، استطاع

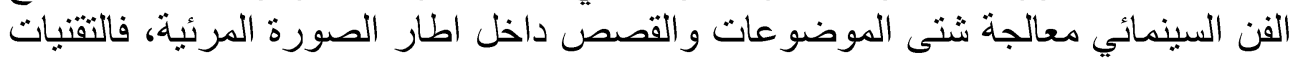

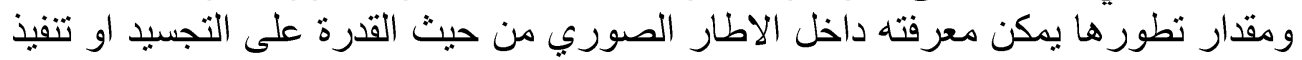

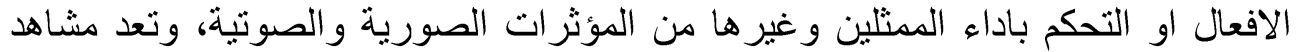

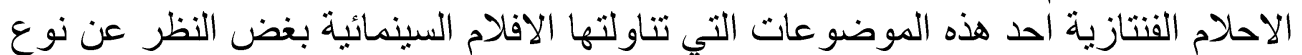

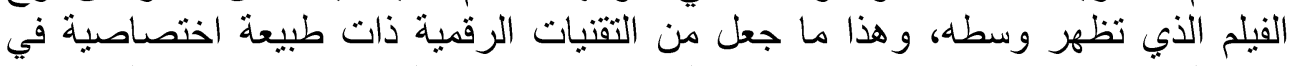
صناعة هذا النوع من المشاهد السينمائية، فالتقنيات الرقمية او السينما الرقمية امتلكت

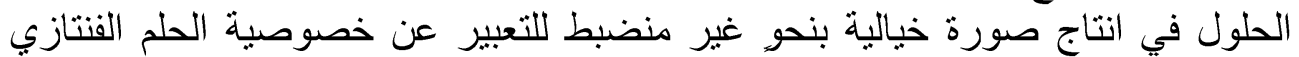

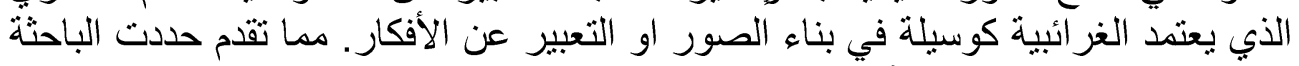

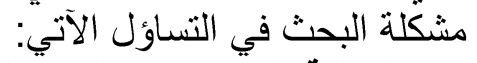

ما الكيفية التي يتم بها البناء الصولي: الصوري لمشاهد الاحلام القنتازية في السينما الرقمية؟

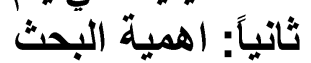

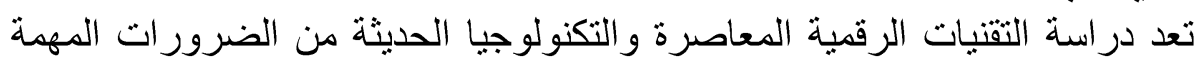

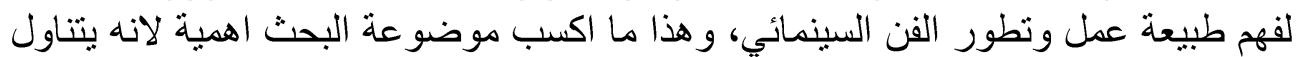

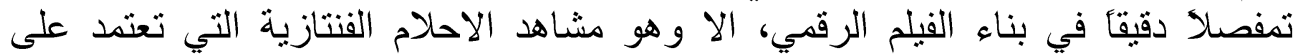

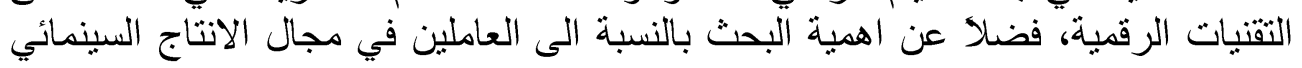
و التلفازي وكذللك الدر اسين و النقاد. ثُالثاً: هدف البحث

يهدف البحث الى دراسة: الكثف عن البحث الكيفية التي يتم بها البناء الصوري لمشاهد الاحلام

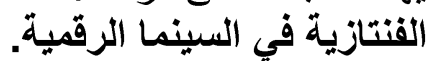

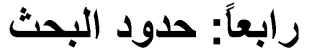

الحد الموضوعي: البناء الصوري لمشئ لمشاهد الاحلام الفنتازية في السينما الرقمية.

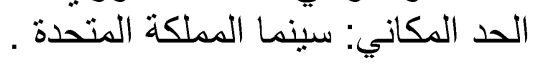

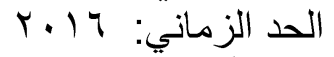
خامساً: تحديد المصطلحات الحمث: خامليا:

التعريف الاجر ائي للحلم: سلسلة من الصور البصرية والتخيلات الذهنية تظهر عبر

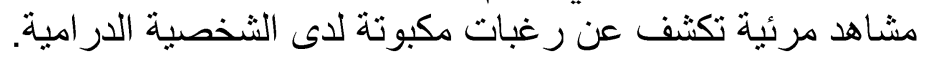

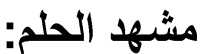

التعريف الاجرائي لمشهد الحلم : مجموعة من الصور الذهنية المترابطة احياناً

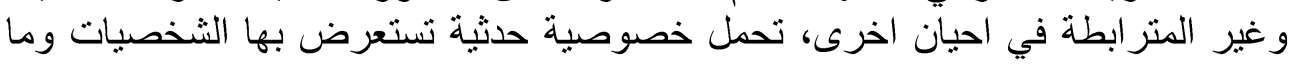

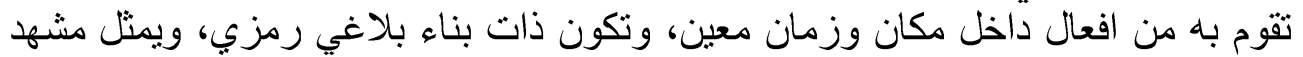

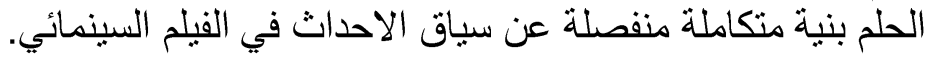


التعريف الإجرائي للفنتازيـا هو : بنية خبالية غير منطقية تتجاوز القوانين؛ لانها

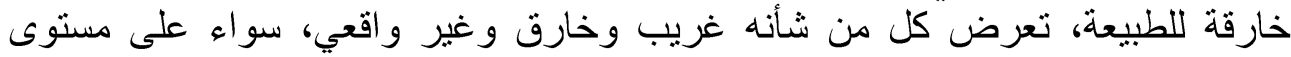
الافعال او الثخصيات هدفها اثثارة الدهنة فنائه والانبهار عند المتلقي. الفصل الثثاني

(الاطار النظري والاراستات السابقة)

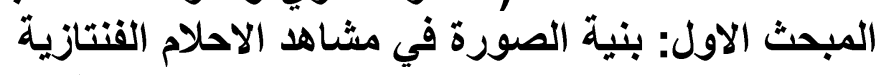

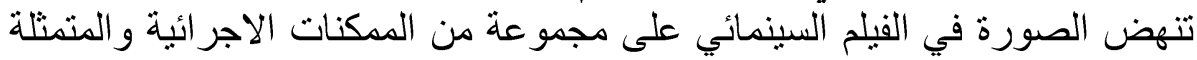

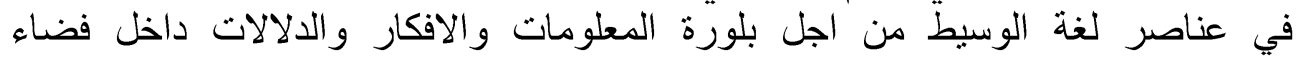

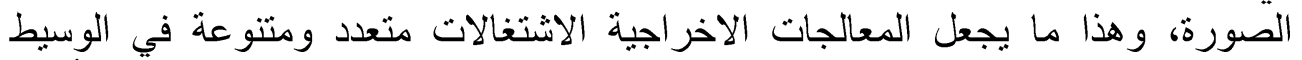

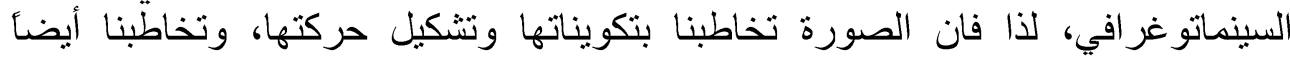

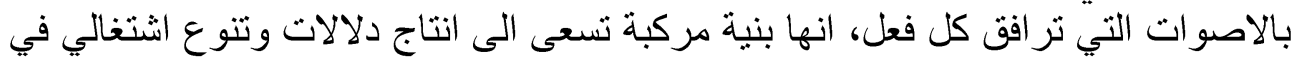

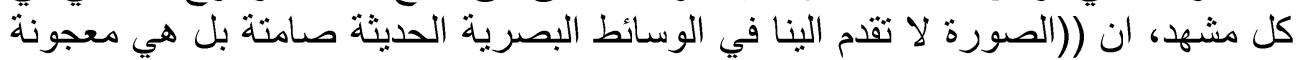

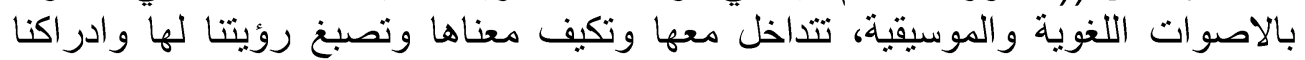

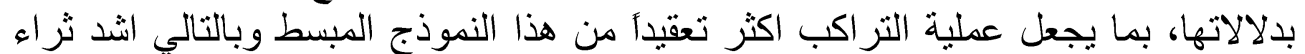

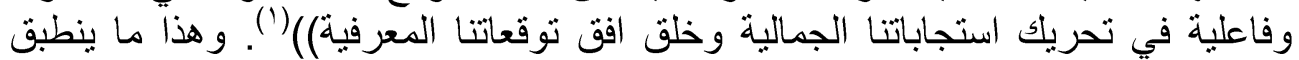

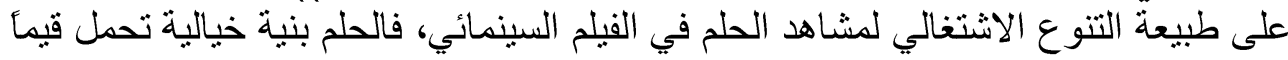

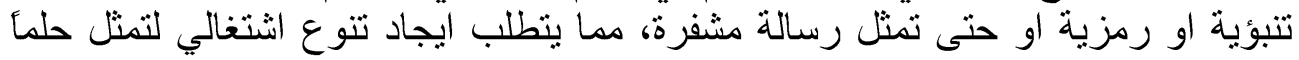

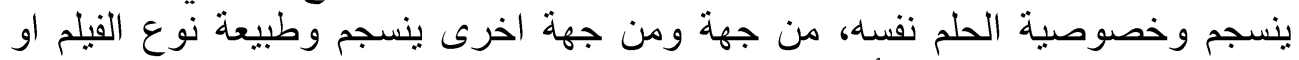

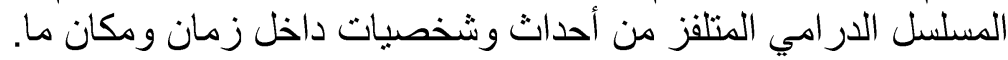

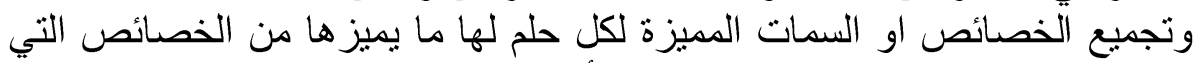

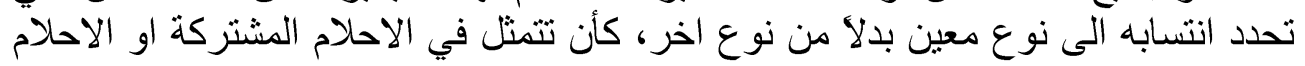

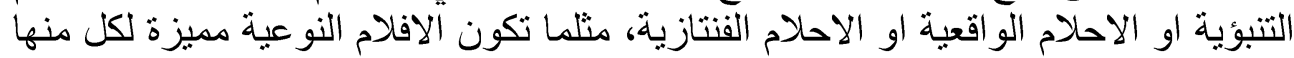

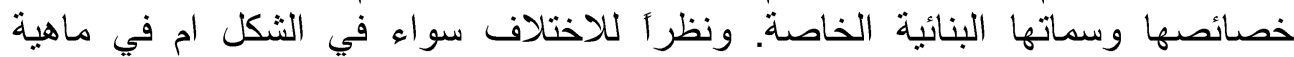

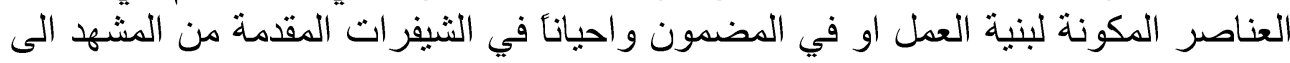

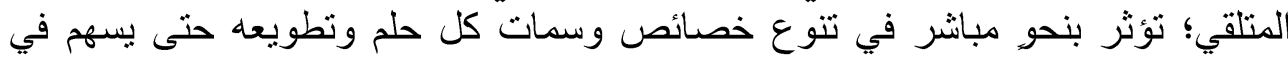

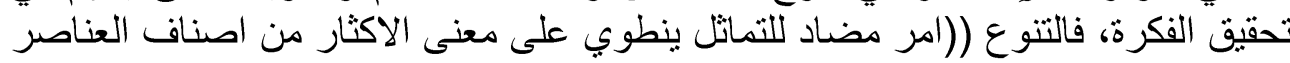

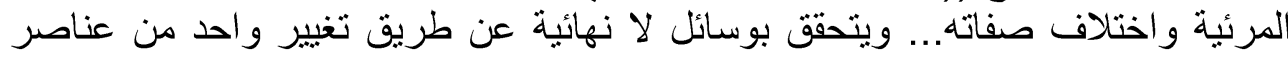

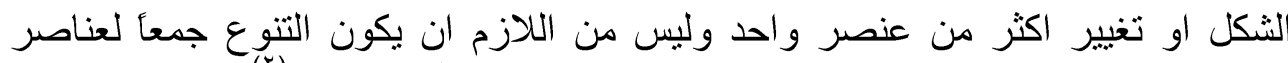

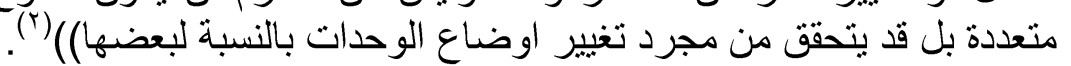

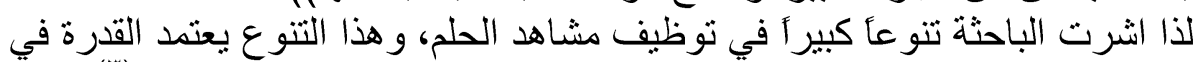

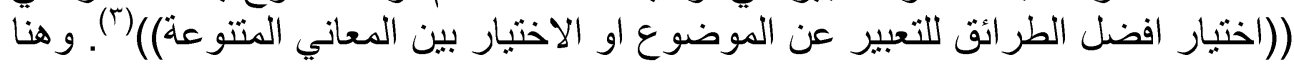

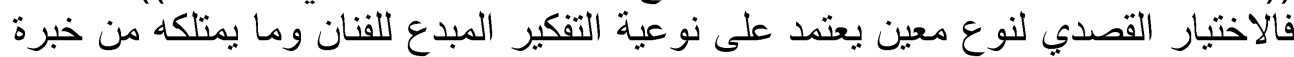

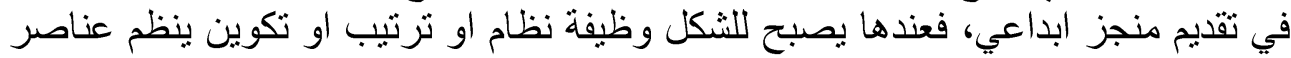

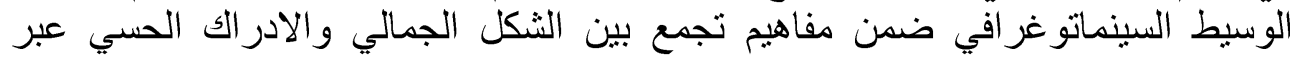

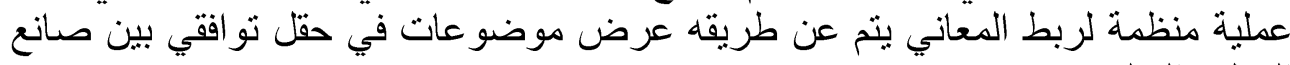

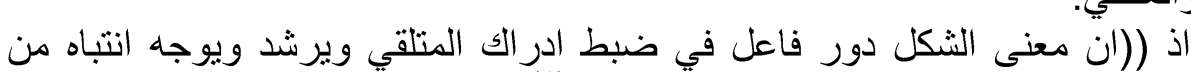

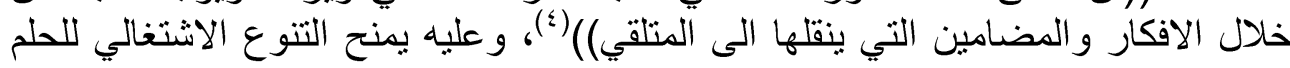




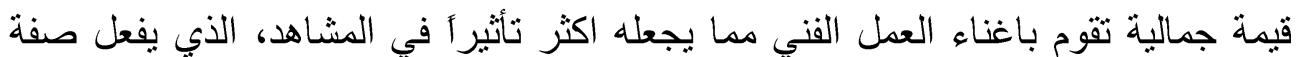

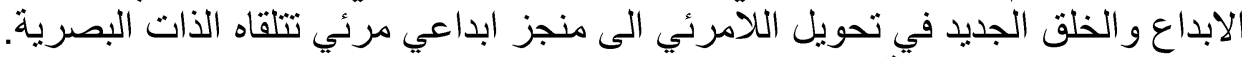

\section{مشاهد الاحلام القنتازية الخية}

تمثل قصص الفنتازيا من الموضوعات الرائجة في الانتاج السينمائي و المتلفز ، وهذا

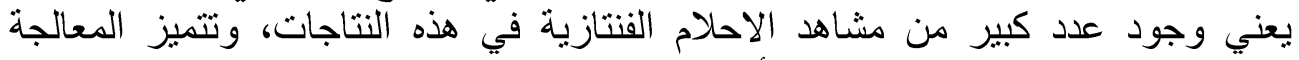

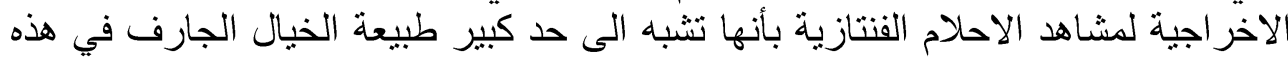

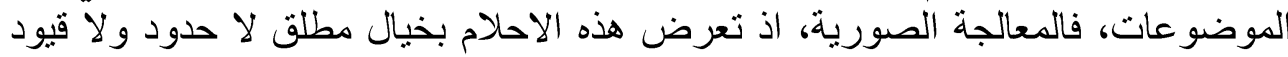

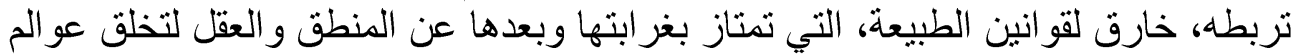

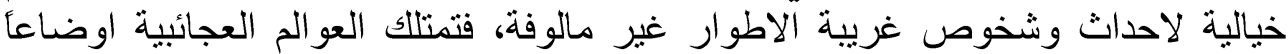

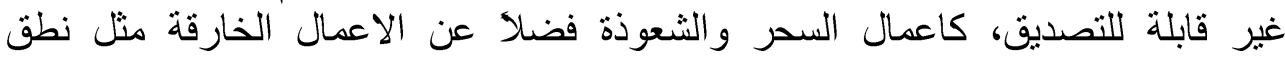

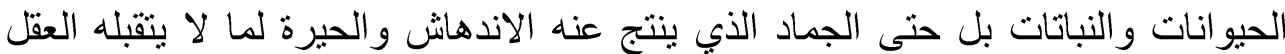
و المنطق للقو انين السائدة في عالنئ المنا الو القعي.

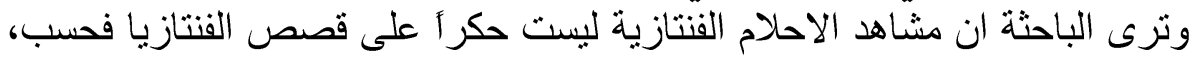

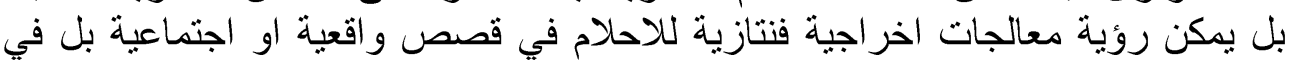

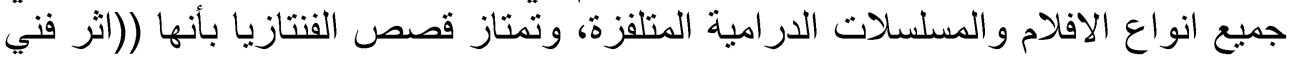

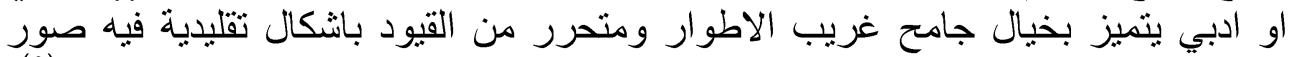

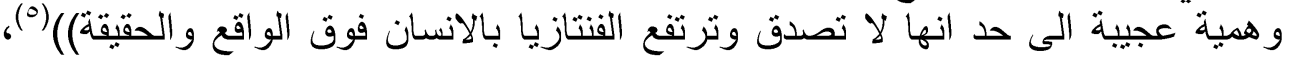

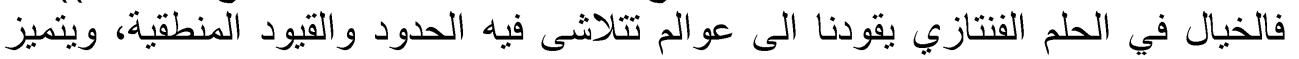

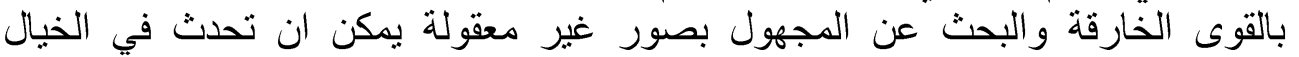

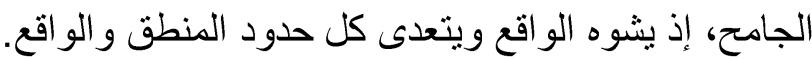

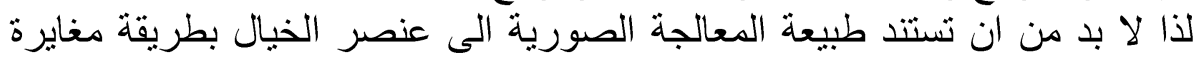

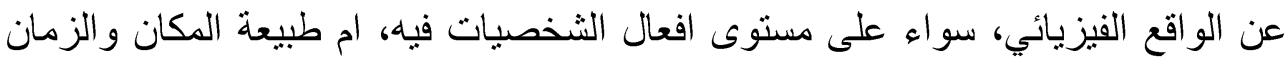

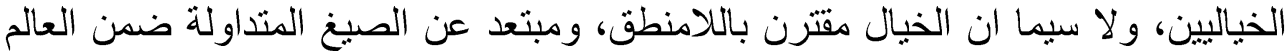

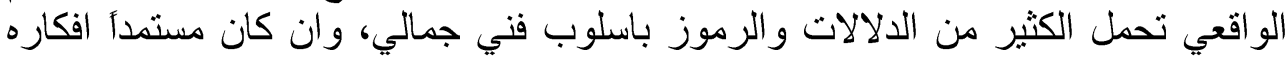

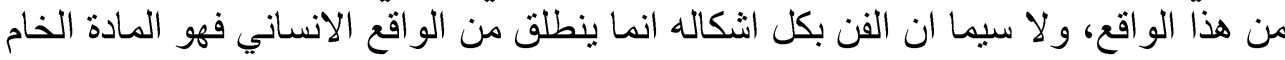

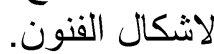

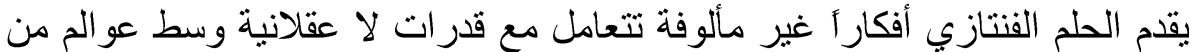

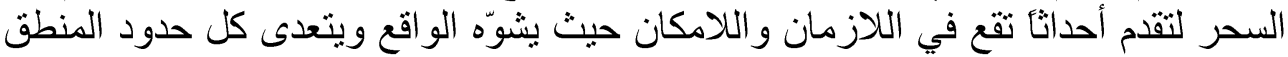

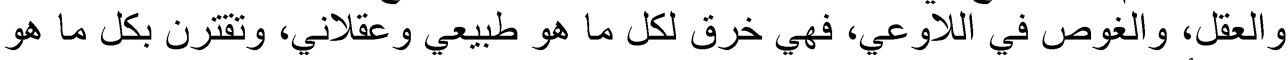

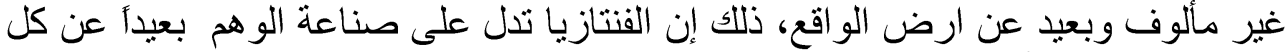

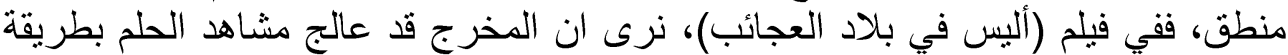

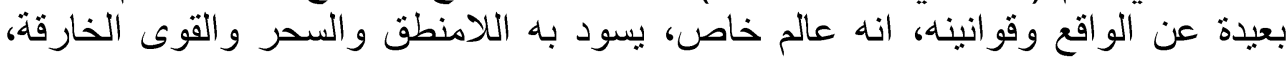

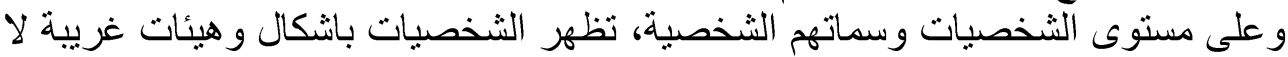

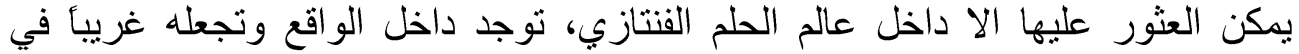

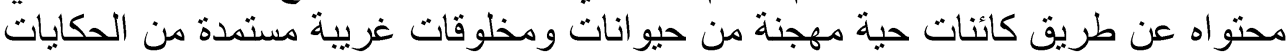

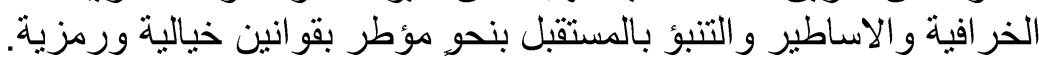

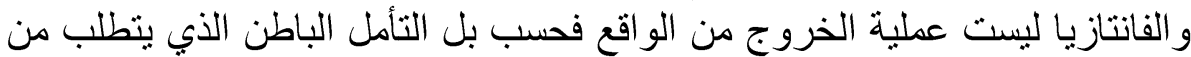

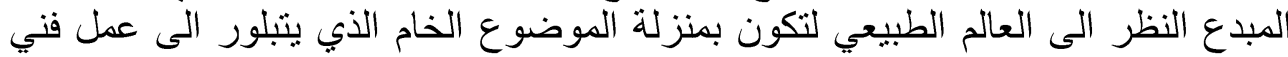

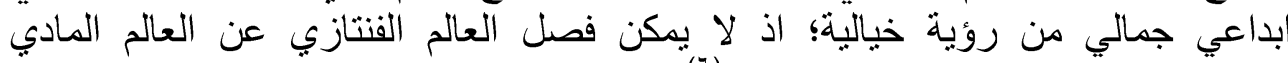

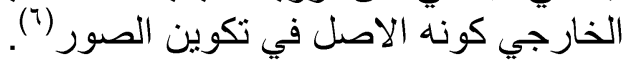


في فيلم (الجزيرة الخيالية Fantasy Island)، للمخرج (جيف و ادل) حول السيد

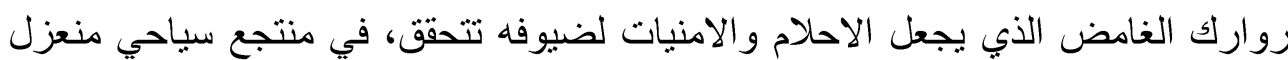

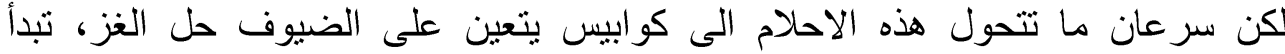

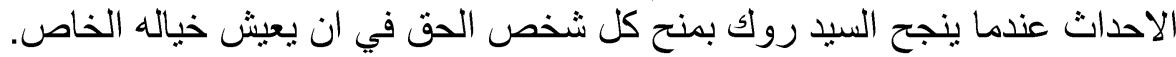

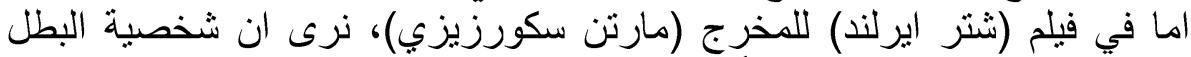

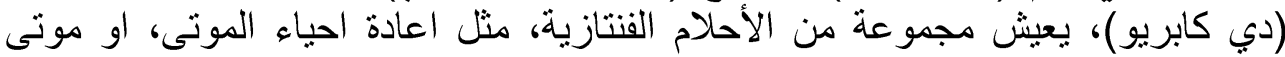

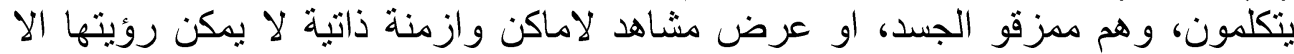

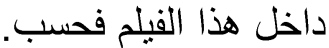

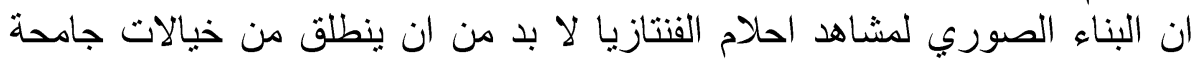

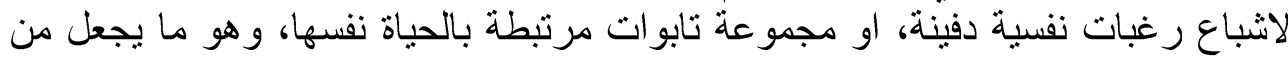

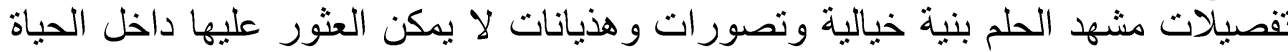

تهيمن على فضاء احلام الفتنازيا العديد من القوى الخارقة، او الافعال غير المألوفة،

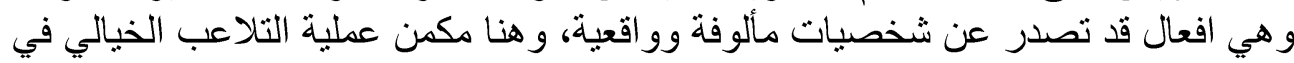

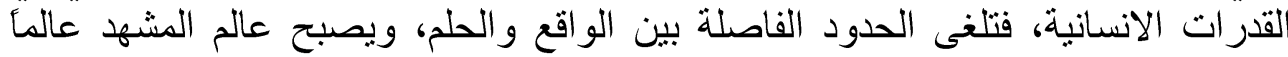

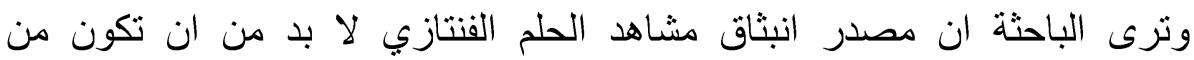

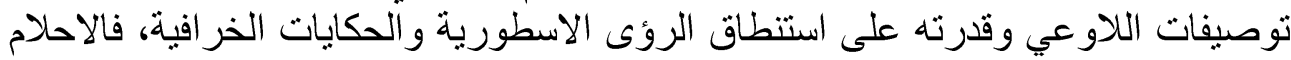

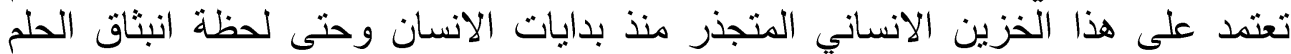

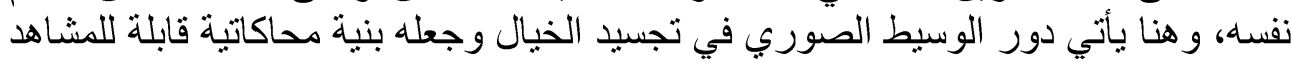
والفهم ولا سيما ان الترميز وكذللك البناء البلاغي يكون حاضرأ في صوغ التهان الصورة في

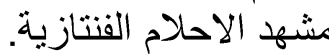

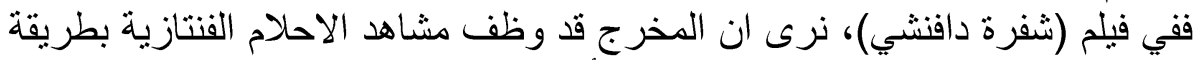

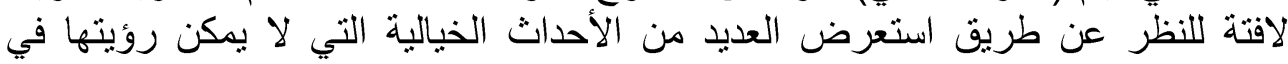

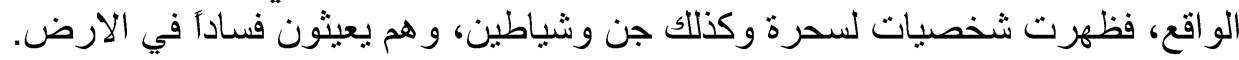

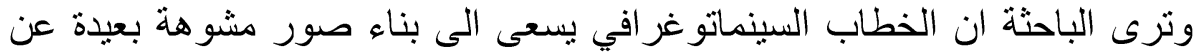

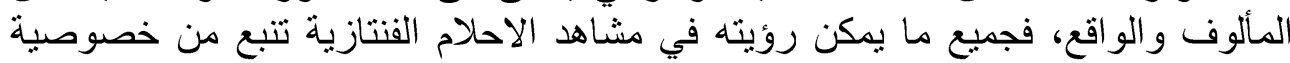

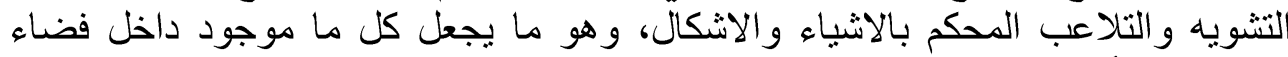

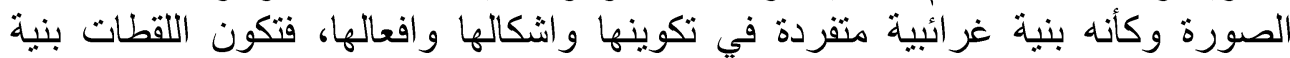

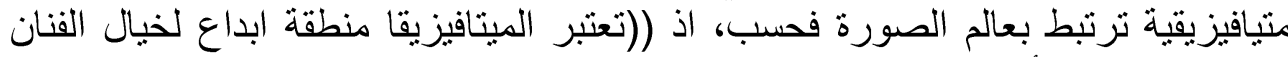

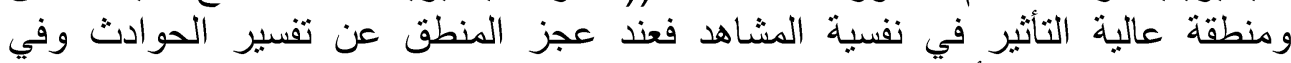

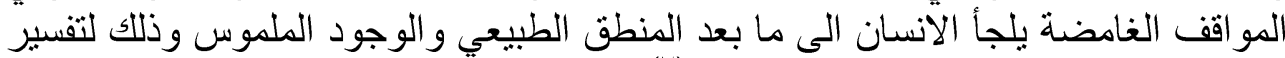

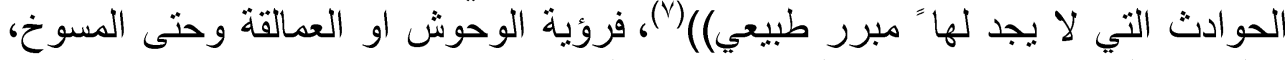

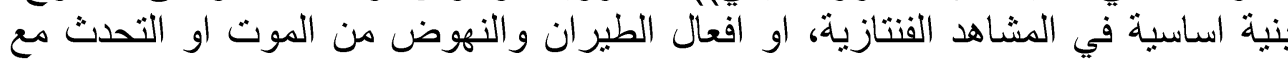

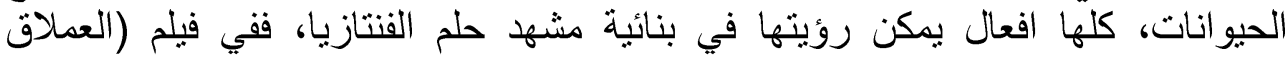

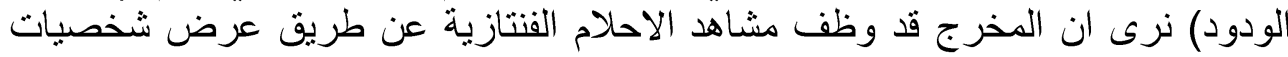

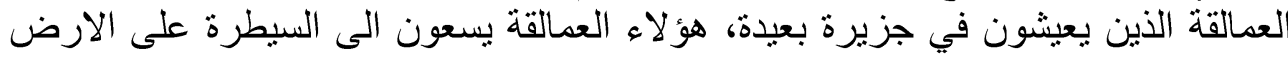
وقهر الانسان، فكانت المثاهد تعبر عن قوة العمالقة وقسوتهم؛ لان طعامهم المفضل هو لأل العان 


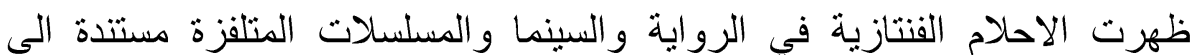
فنتازية القصص الثعبية من ألف ليلة وليلة التي امتازت باعتمادها على الته الخيال بحيث

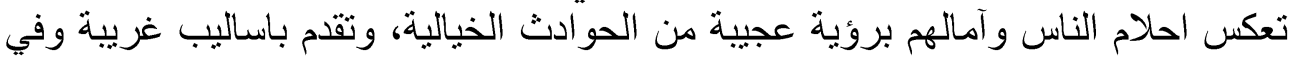
الحديث عن اللامعقول الممزوج الرموز والئه والمعاني الغنية بالدالالات التعبيرية.

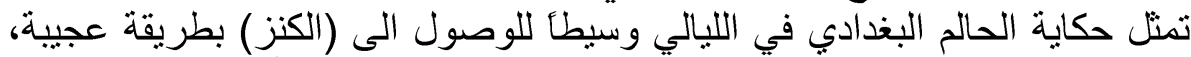

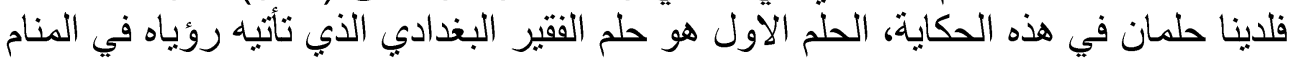

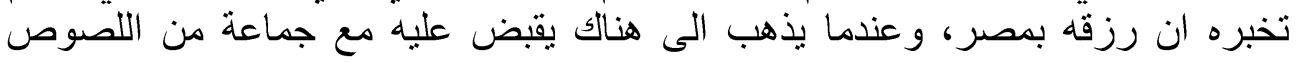

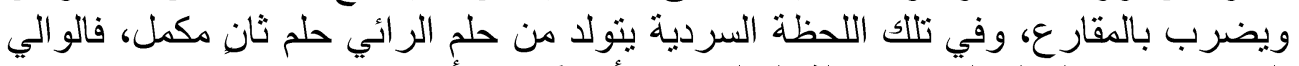

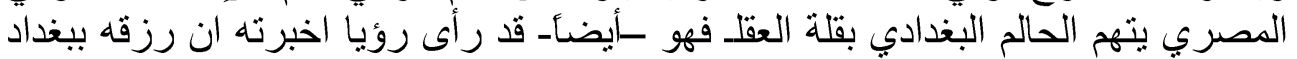

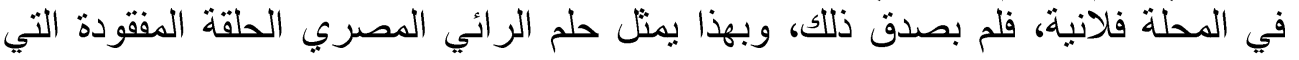

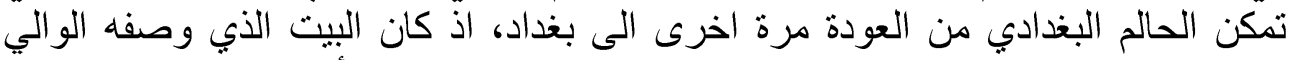

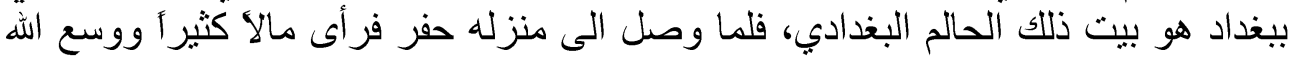

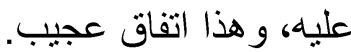

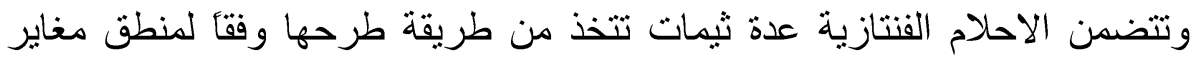

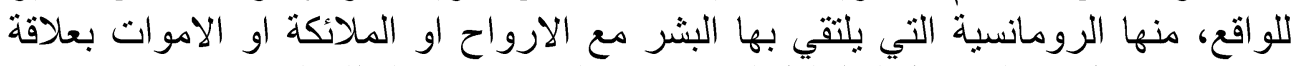

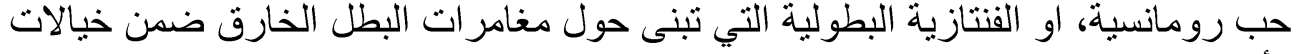

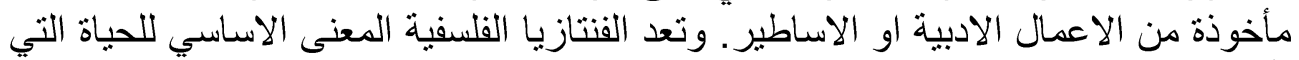

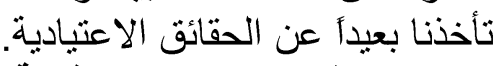
المبحث الثاني: السينما الرقمية الرية الرئة

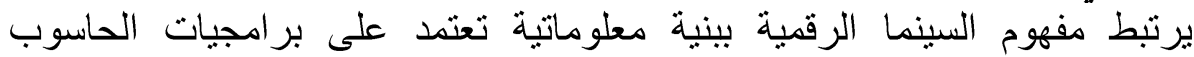
و التكنولوجيا المتقدمة من اجل انتاج الصور المرئية رقمياً اعتماداً على النظام الثنائي

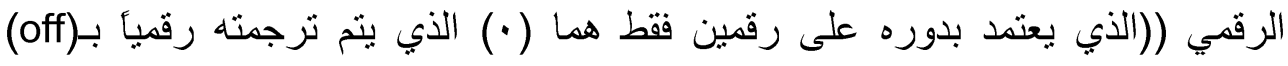
و الواحد (1) الذي يتم ترجمته رقمياً بـ(one) ويأخذ كل رقم شكل اشارة ثنائية بمعلومة

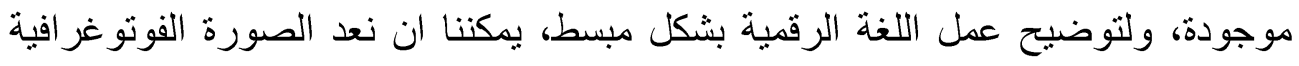

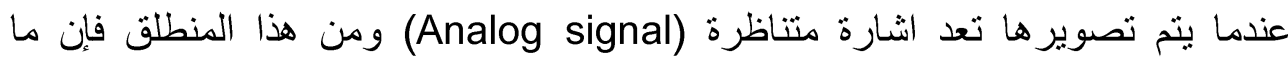

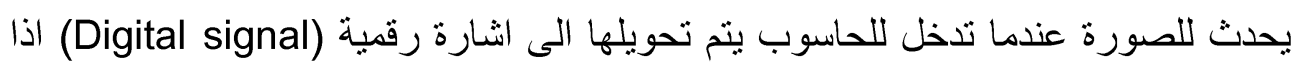

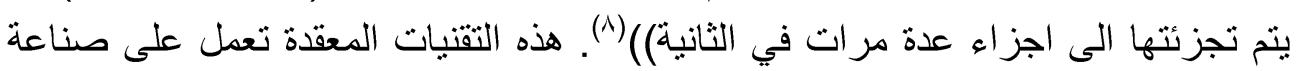

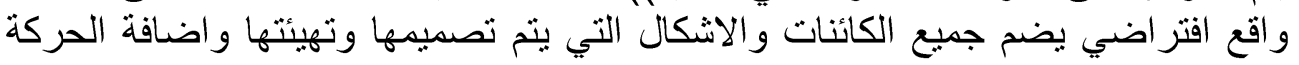

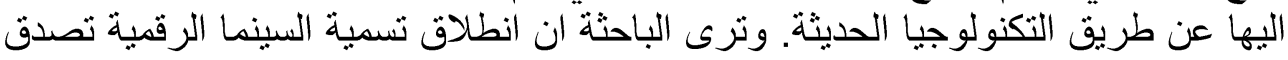

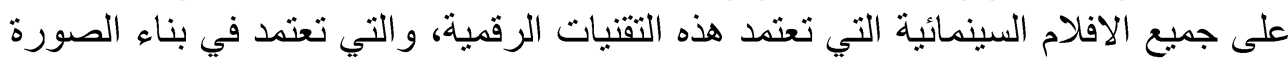

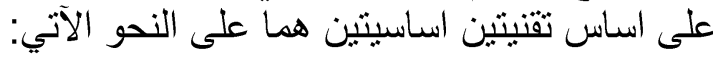

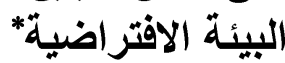

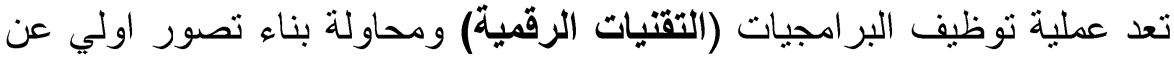

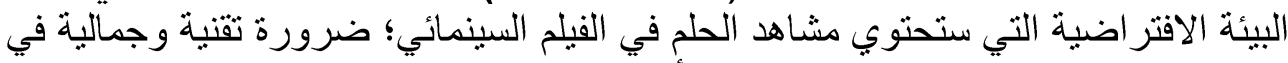

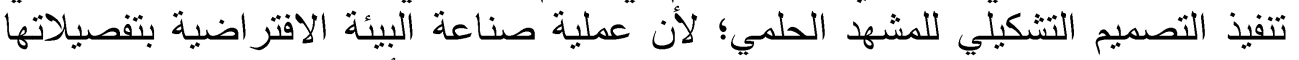

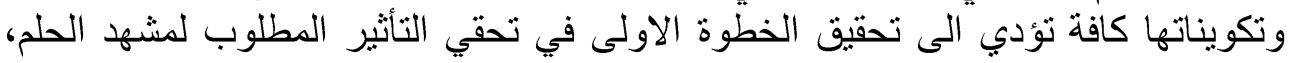

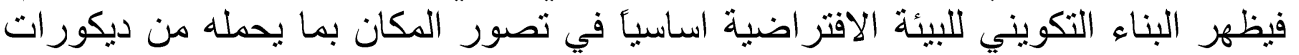

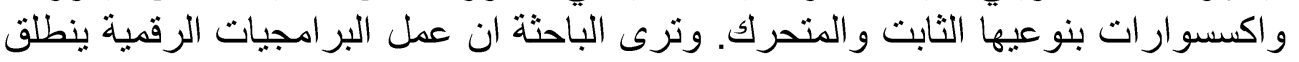

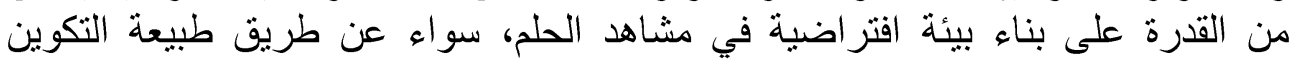




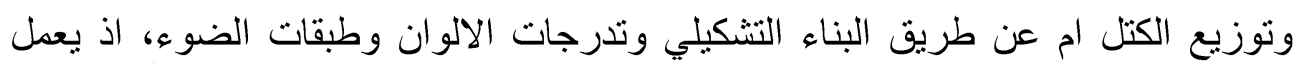

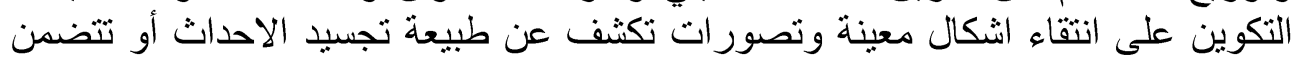

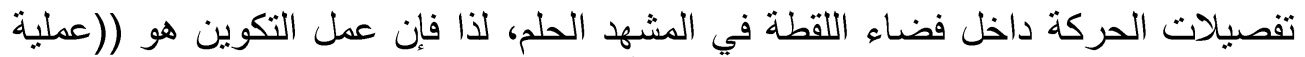

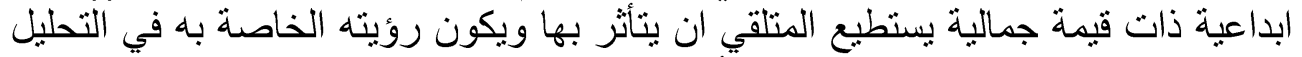

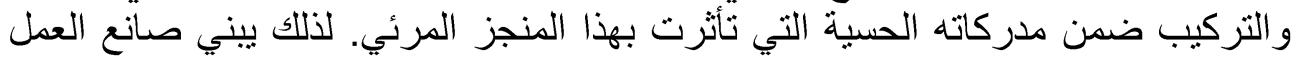

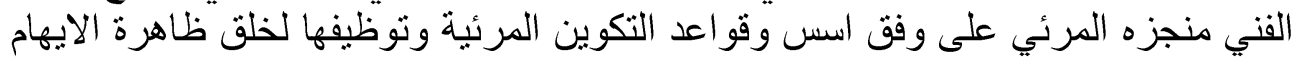

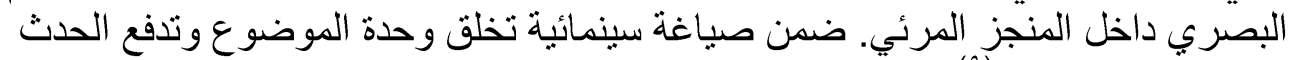

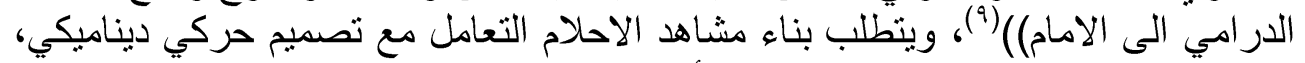

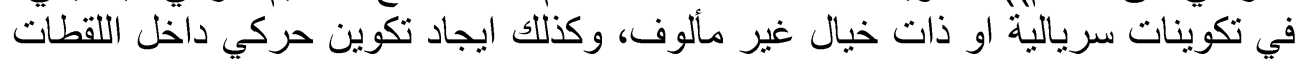

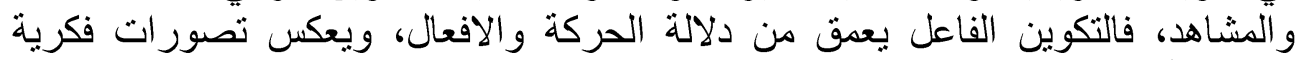

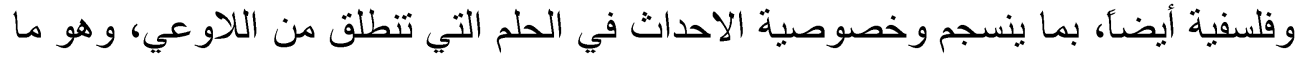

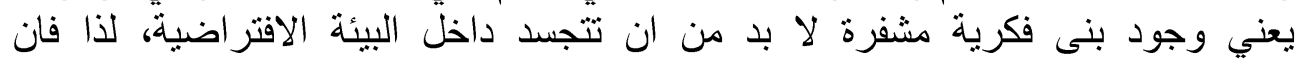

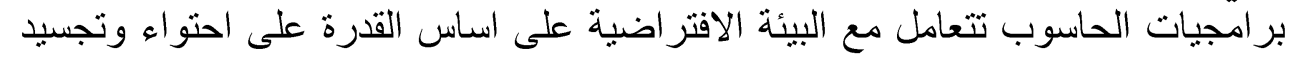

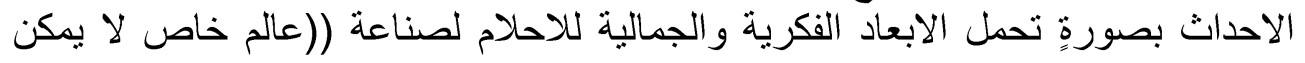

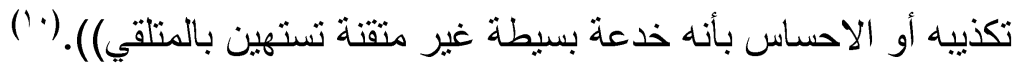

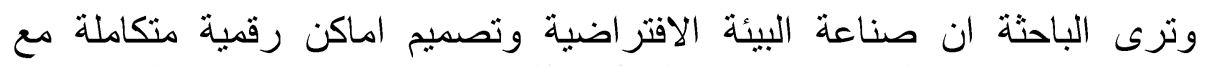

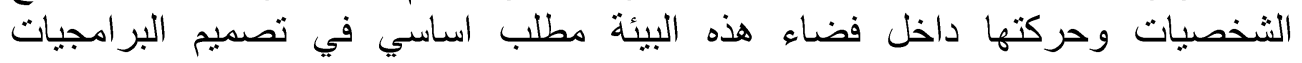

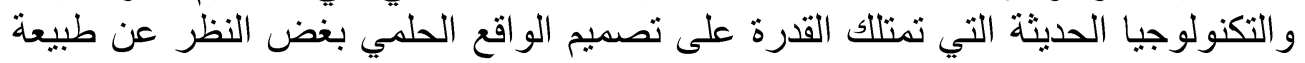

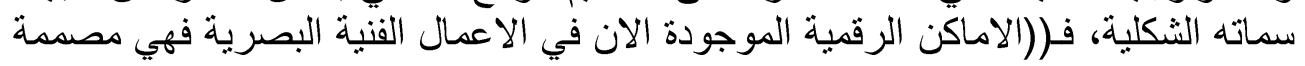

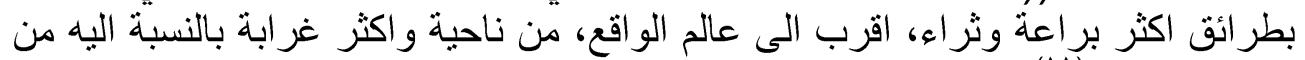

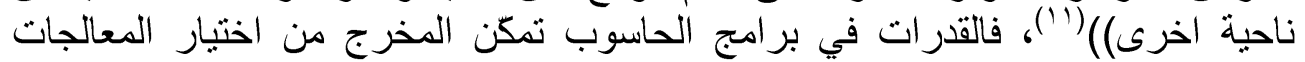

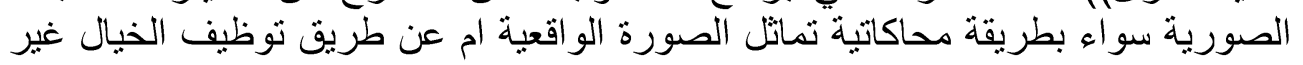

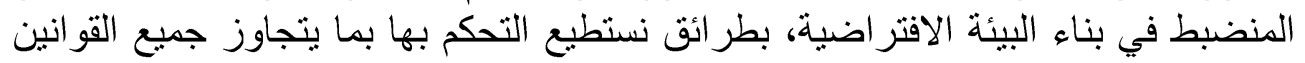

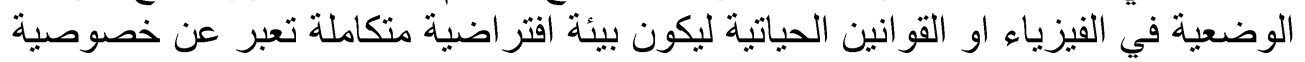

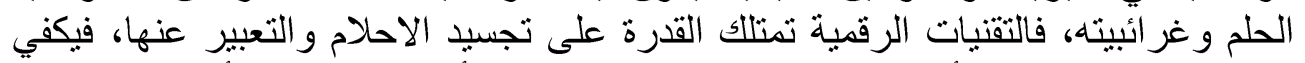

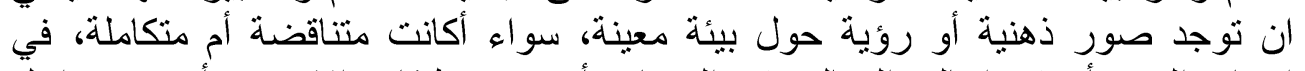

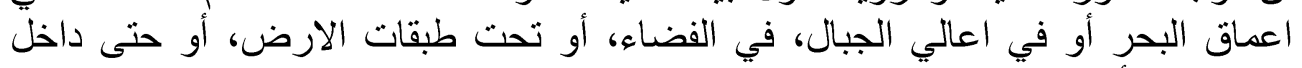

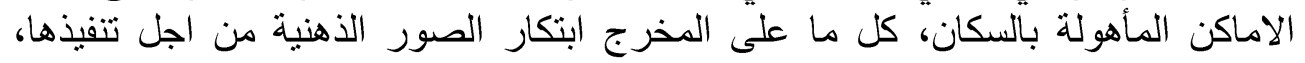

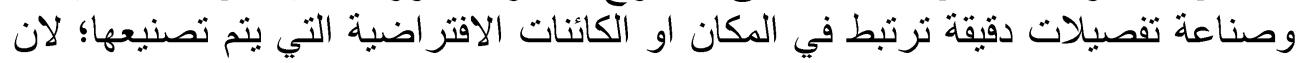

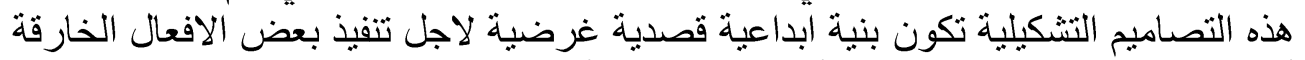

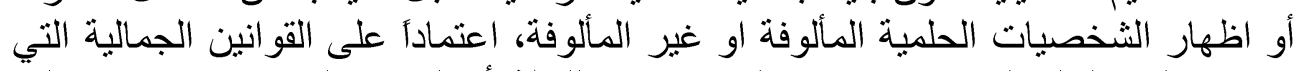

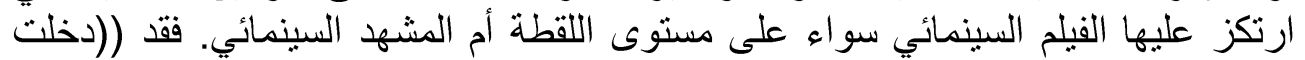

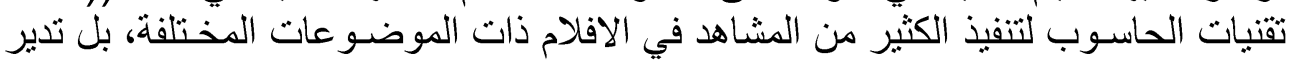

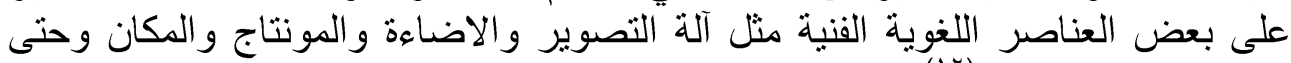

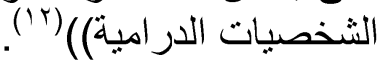

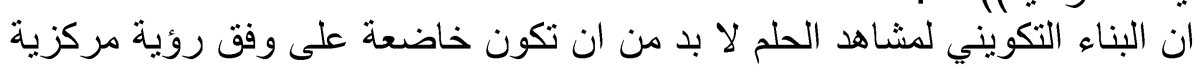

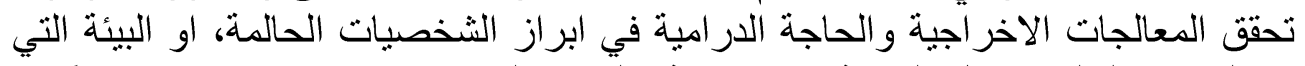

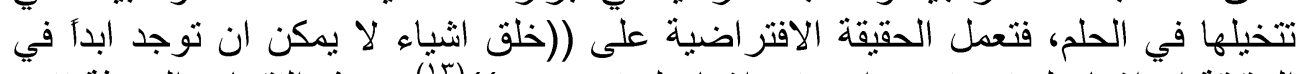

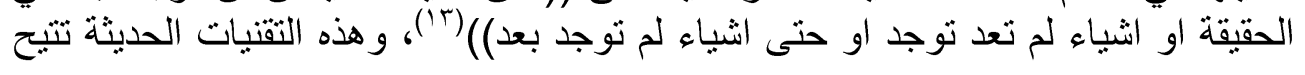


للمخرج امكانيات صناعة بيئة مشاهد الحلم بطريقة جديدة متفردة عبر توظيف كل ما هو غريب و غير مألوف داخل فضاء الصورة في الفيلم السبنمائي.

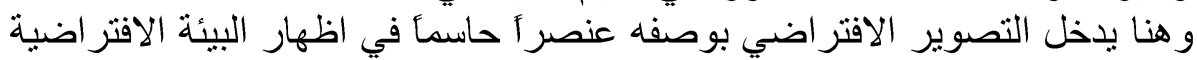

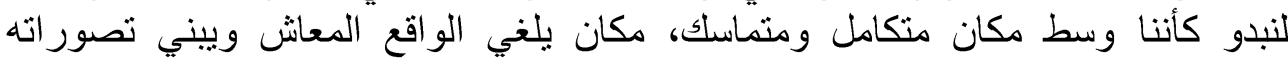

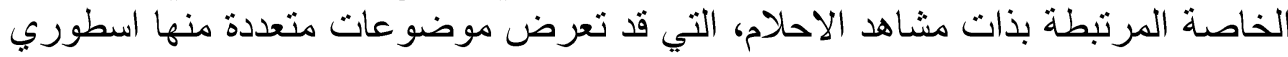

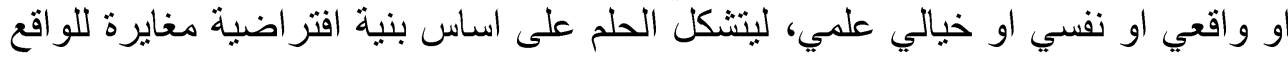

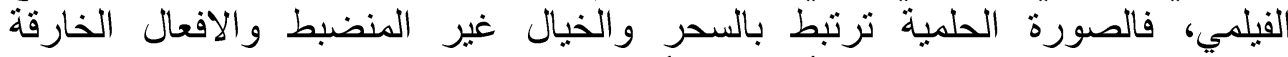

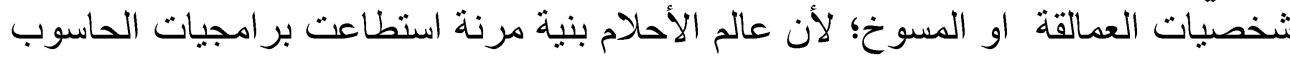

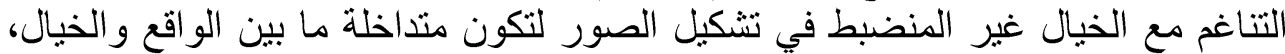

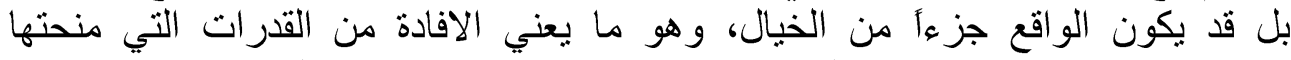

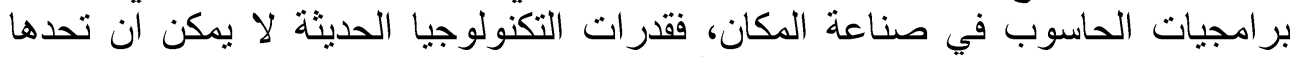

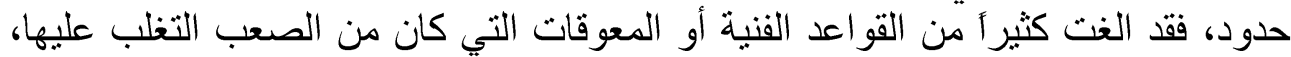

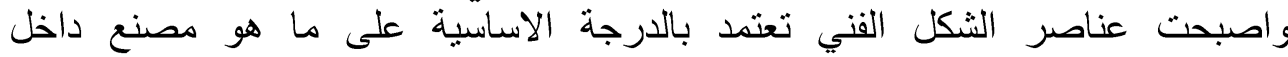

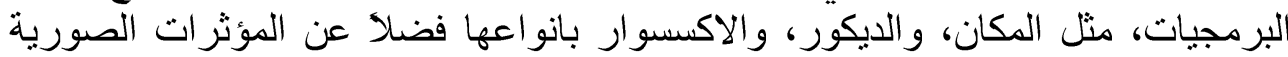
الرقمية.

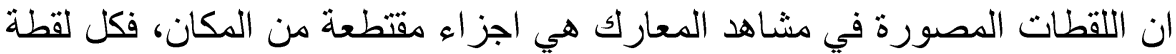

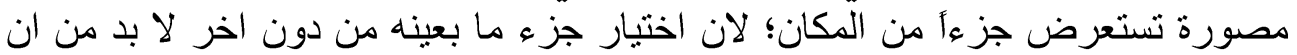

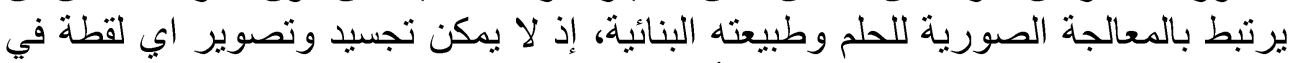

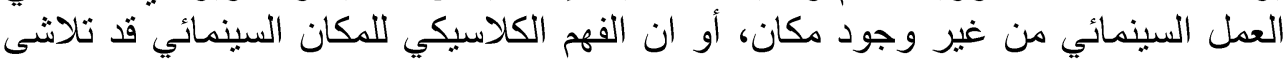

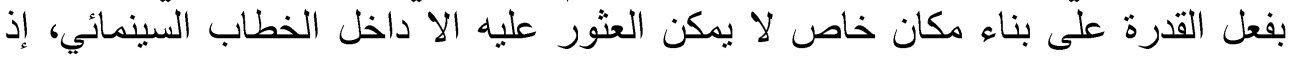

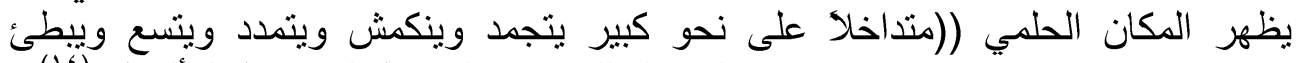

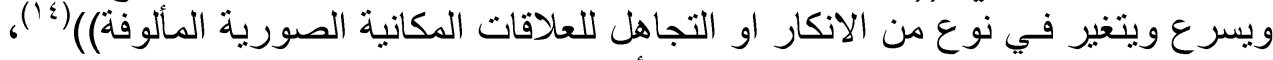

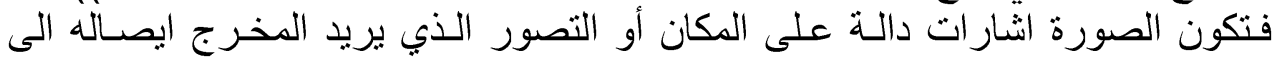

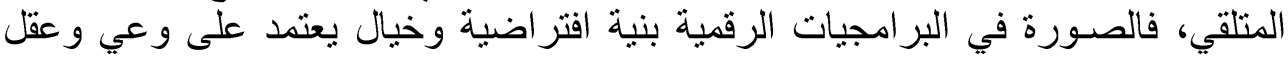

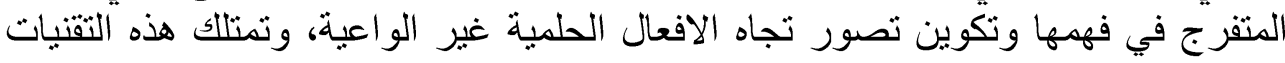

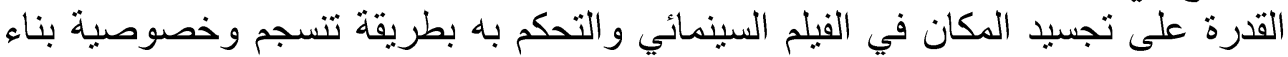

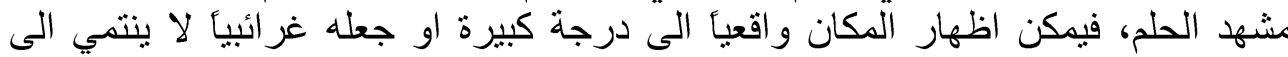

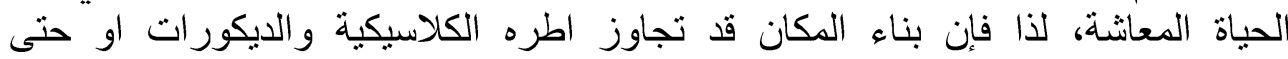

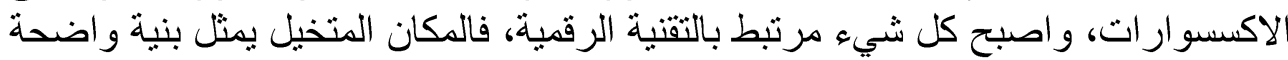

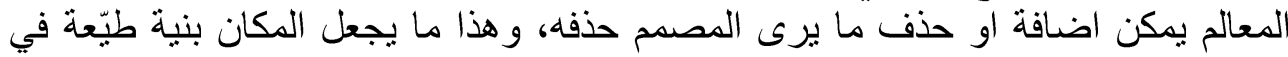

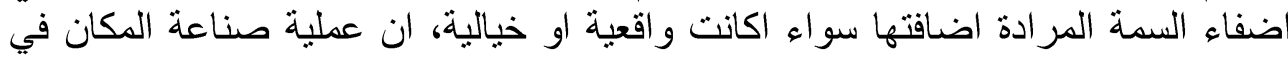

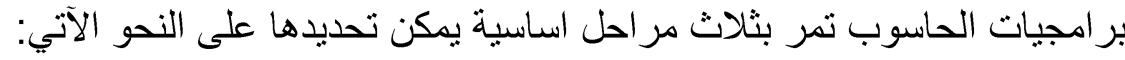

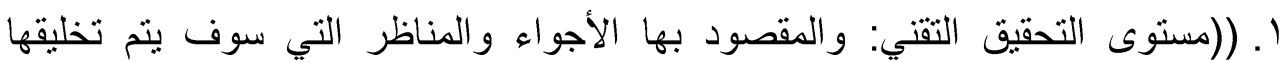
بو اسطة الحاسوب. (استوب.

Y. مستوى الحقيقة (الواقعية): يجسده الممثل الذي يتفاعل مع المعطيات الافتر اضية حينما يؤدي الأدوار المطلوبة منه وتحيط به الخها الخلفية (الكروما).

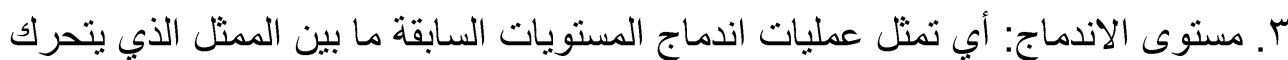

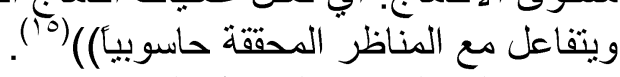

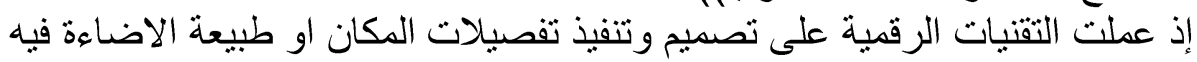

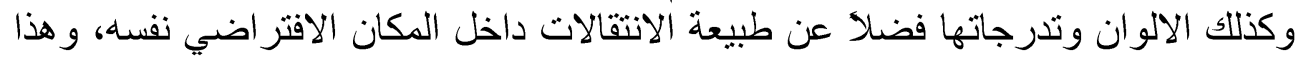




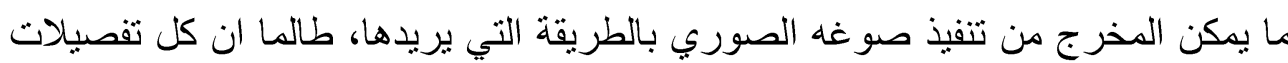

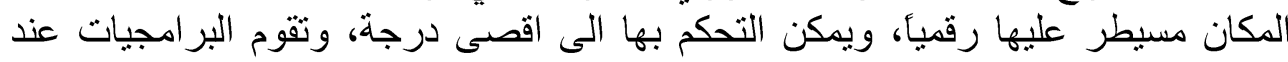

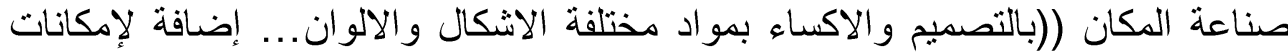

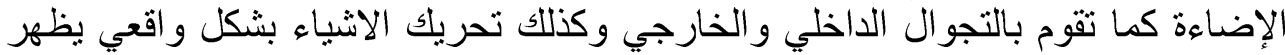

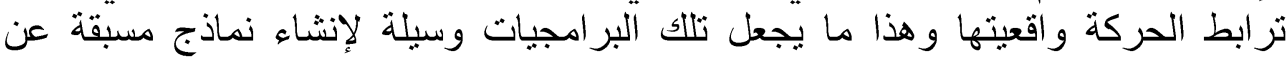

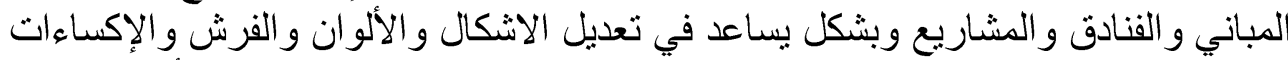

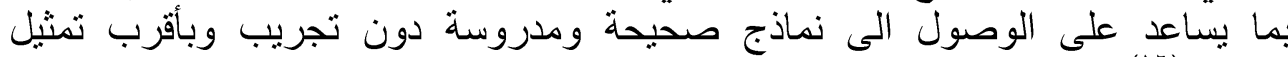
للو اقع)(ان) (17)

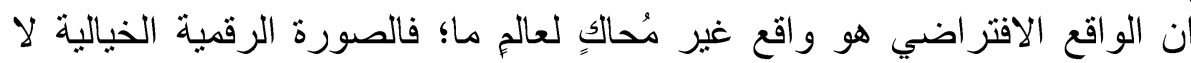

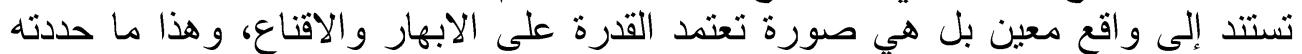

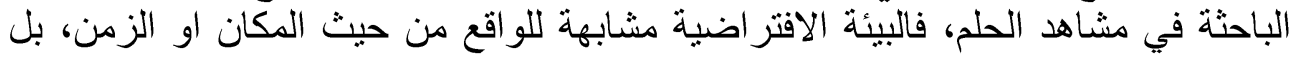

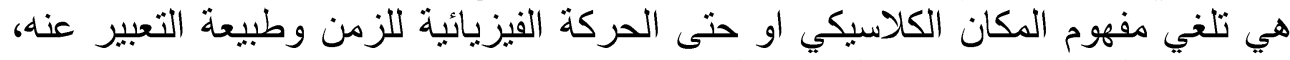
انهاً تسعى الى التفرد في بناء المكان و الزئي الزمان.

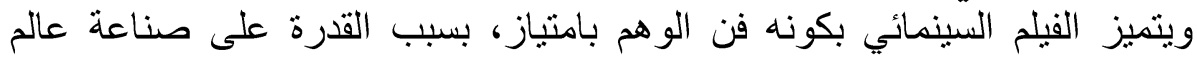

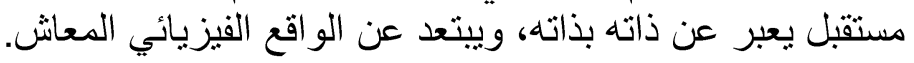

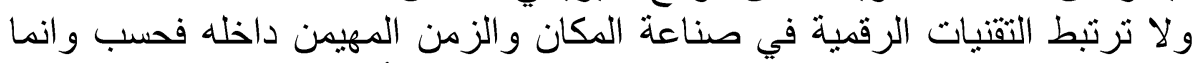

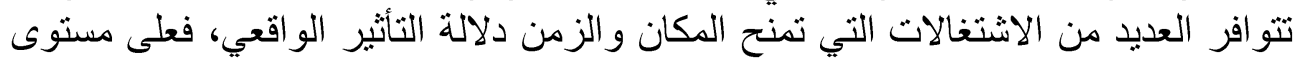

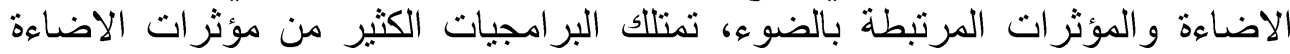

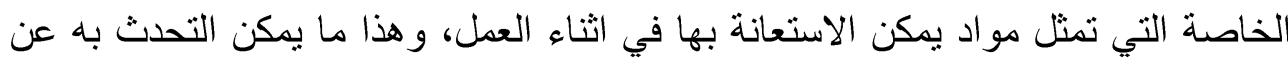

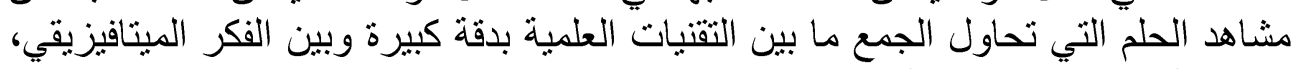
داخل اطار الصورة الحلمية.

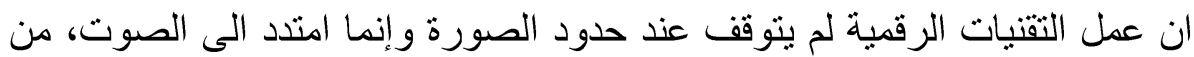

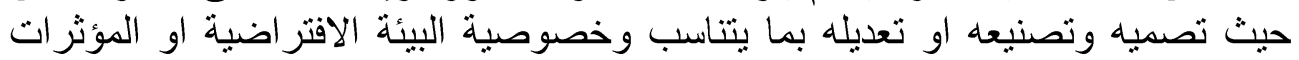

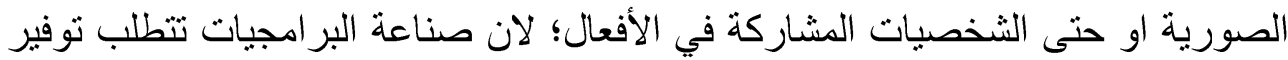

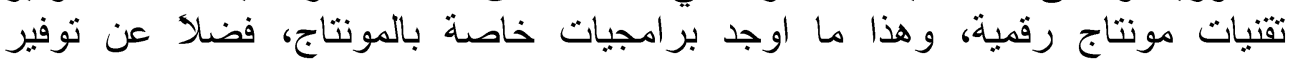

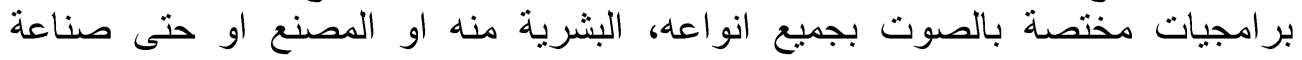

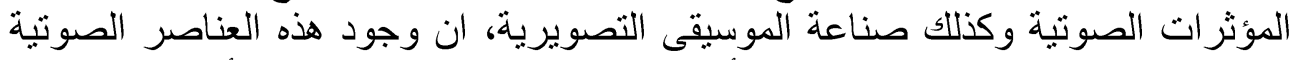

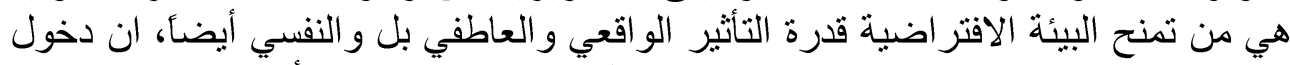

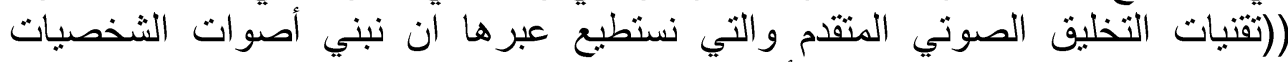

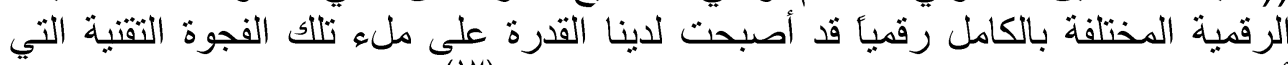

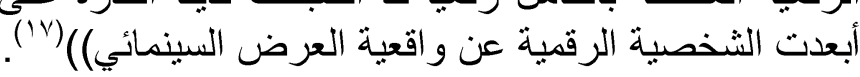

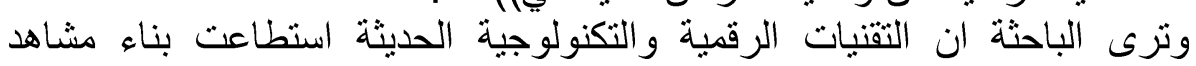

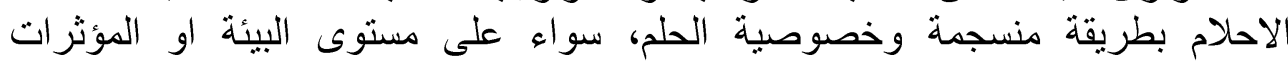

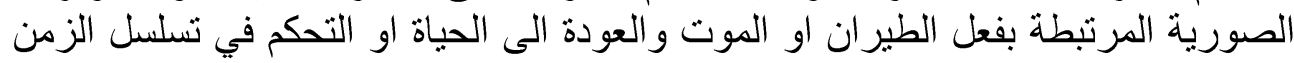

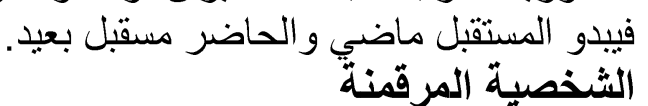

لم تتوقف التقنيات الرقمية والتكنولوجية المعاصرة على بلى بناء البيئة الافتراضية

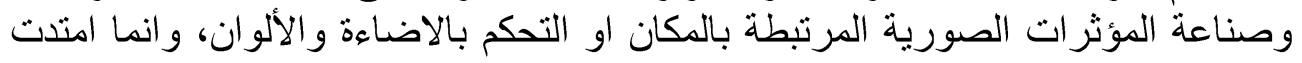
نحو صناعة الثخصية الرقمية، وهو ما اوجد مساحة اشتخال جديدة للمخرجين في تناول 
شتى انواع الشخصيات بغض النظر عن كونها و اقعية ام مسوخأ ام عمالقة، ام شخصيات

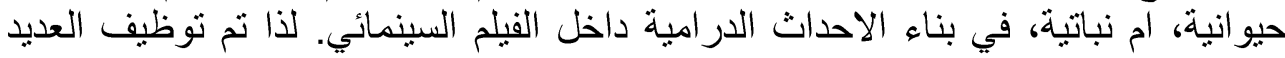

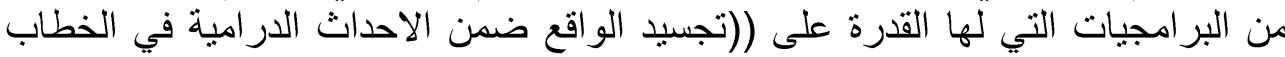

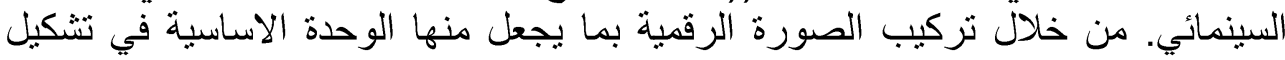

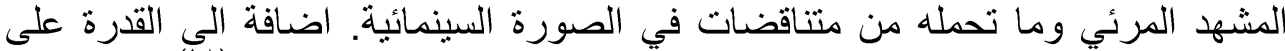

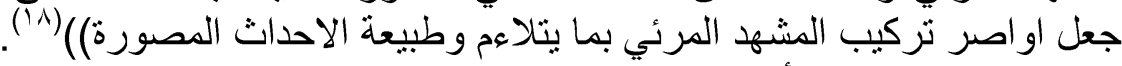

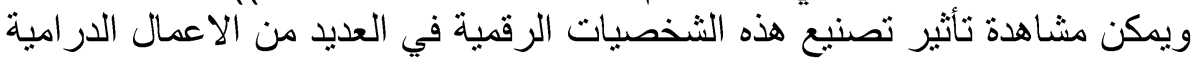

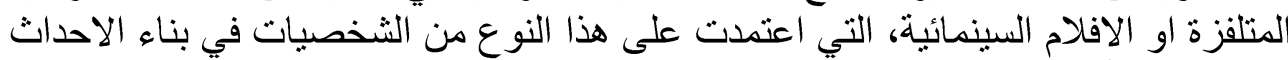

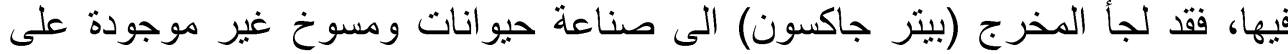

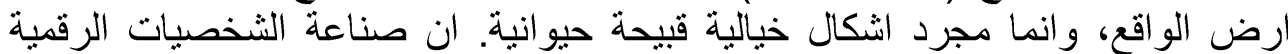

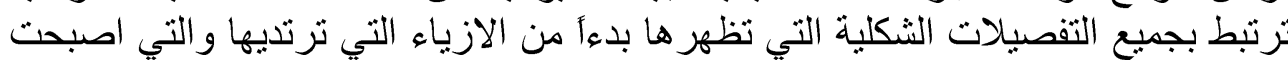

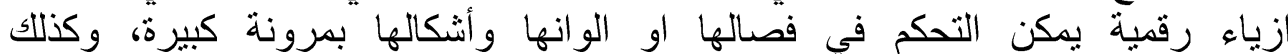

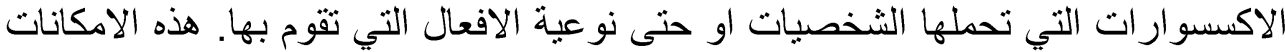

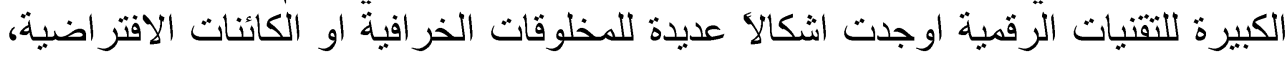

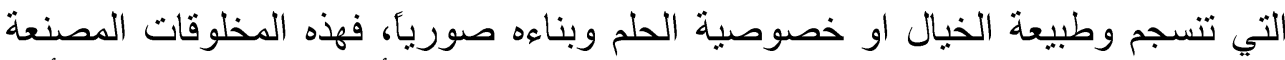

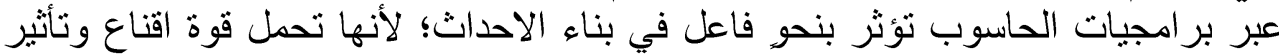

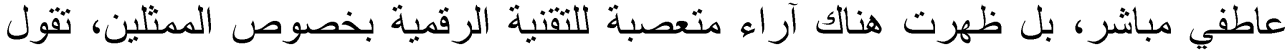

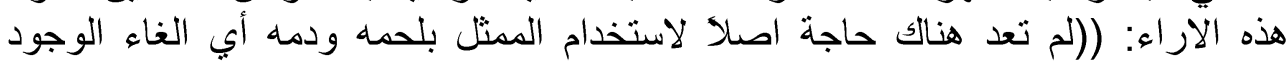
المادي للممثل، والاستعانة بنظم المحاكاة الحديثة للشخصية البشرية (الهيئة الصورية) مثل الصن النظام الحركي الذي ابتدعته شركة (UBI SOFT) عبر نظام ( CRYTECH ENIGNE)

كانت بدايات ظهور التقنيات الرقمية المرتبطة بتصنيع الثخصية الرقمية في سنة

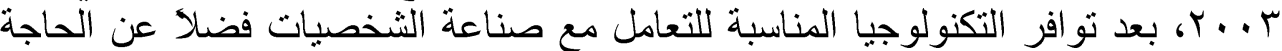

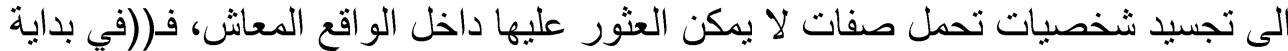

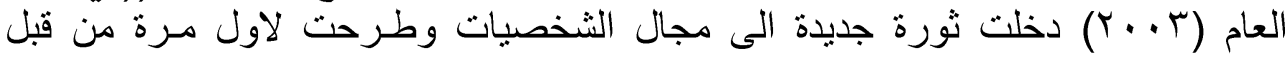
صانع الافلام الصيني (Ing Lee)، فكرة التخلي عن الممثل بعدما نجح في حل معضلة فيلة

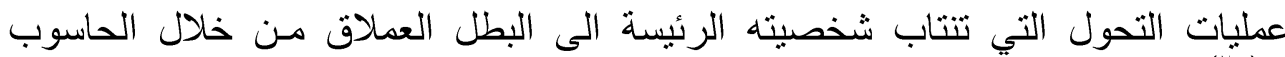

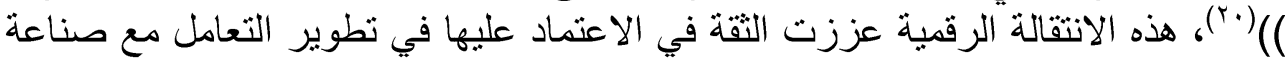

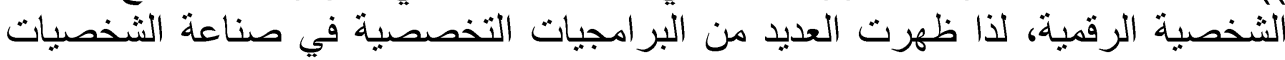
على وفق برامج التقاط الحركة (mo cap)، وهي تقنية اساسية في صناعة الثخصيات

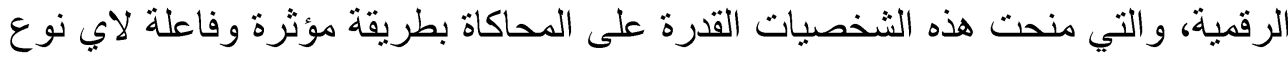

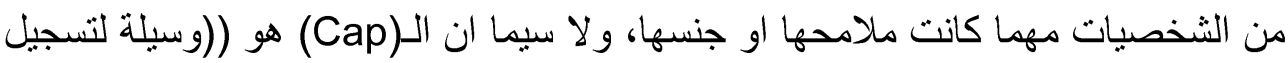

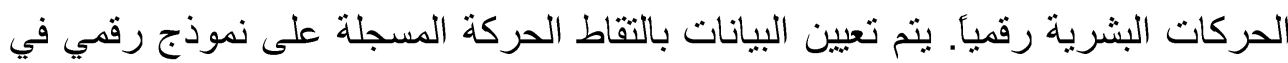
برنامج 3D (على سبيل المثال حركة غير واقعية، وحدة 3D مايا أو 3D ستديو ماكس) حتى يتحرك الطابع الرقمي مثل الممثل الذي سجلت. يتم استخدام التكنولوجيا (MO Cap)

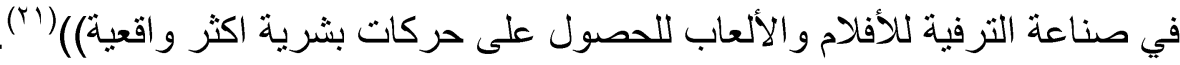

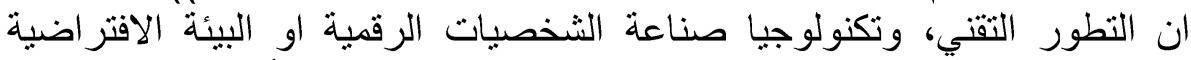

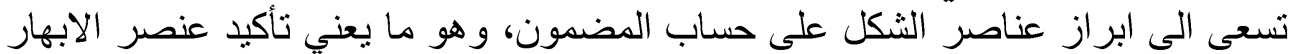


الصوري، فالصناعة الرقمية ترتبط بالصوت والحركة والتعبير عن طريق ملامح الوجه، الصنا،

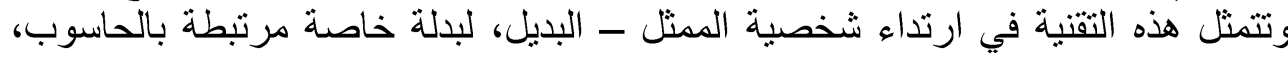

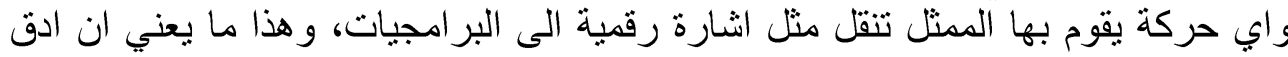

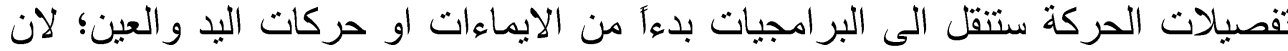

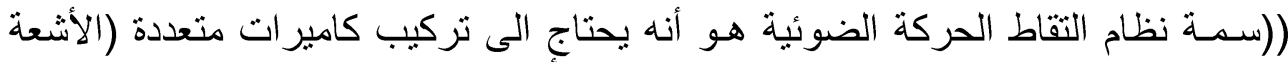

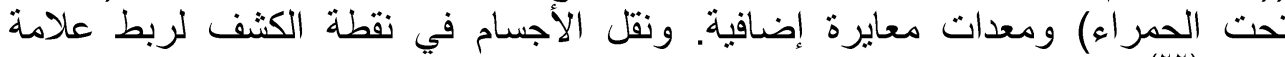
ثنانية)( تح)

اتسعت قدرة بر امجيات الحاسوب في صناعة الصورة بتفصيلاتها كافة، وانتاج بيئة

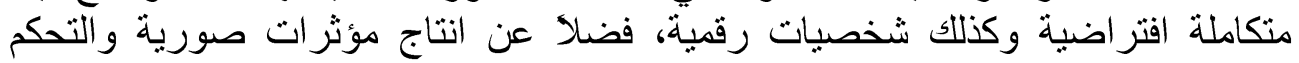

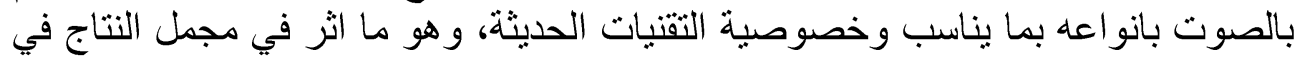

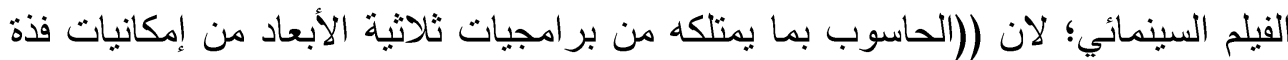

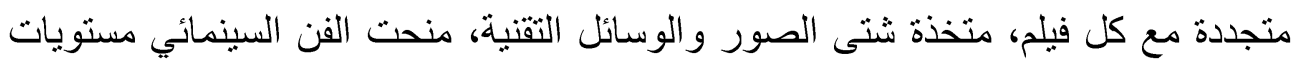

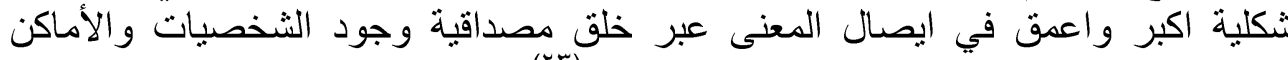

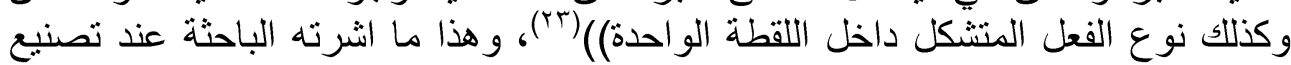

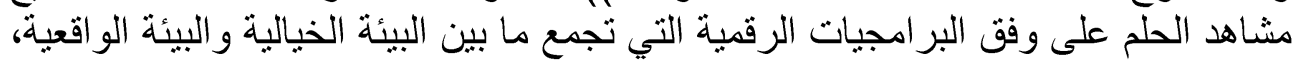

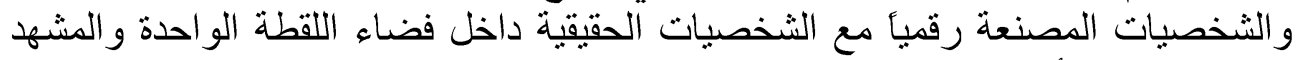

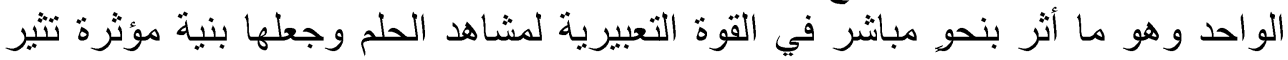

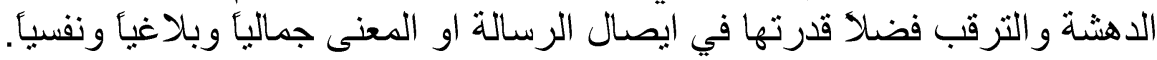
مؤشرات الاطار النظري فئري

ا ـ تعتمد السينما الرقمية على التكنولوجيا المعاصرة الإنية في بناء البيئات الافتر اضية المكونة لبشاهد الاحلام الفتتازية في الفيلم السينمائي.

r. يعد وجود الثخصيات المرقمنة من العناصر الاساسية المشكلة للاحداث الفيلمية لمشاهد

$$
\text { الاحلام الفنتازية. }
$$

r. يتدخل الواقع والخيال الجارف في بناء الاحداث الدرامية في بنية الصورة لمشاهد

$$
\text { الاحلام الفنتازية في الفيلم السينمائي. }
$$

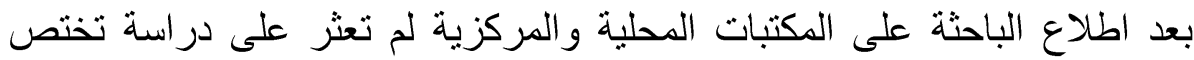

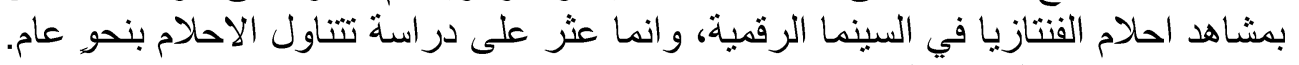
لذا تعد هذه الدر اسة محاولة اولى في هذا لإنى الموضوع.

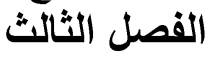

\section{(اجراعات البحث) (البه)}

أولاًا: منهجاً: الداة البحث: البحث:

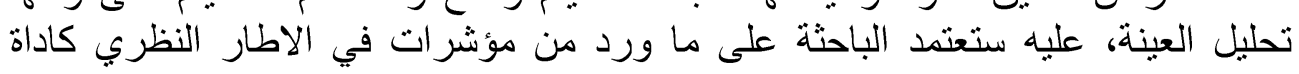


للتحليل بعد عرضها على لجنة الخبراء والمحكمين، وقد حصلت على موافقته، وهي بالنحو الآتي: ا ـ تعتمد السينما الرقمية على التكنولوجيا المعاصرة في بناء البيئات الافتر اضية المكونة لمشاهد الاحلام الفنتازية في الفيلم السينمائي. r. يعد وجود الثخصيات المرقمنة من العناصر الاساسية المشكلة للاحداث الفيلمية لمشاهد الفياني الاحلام الفنتازية. r. بتدخل الواقع والخيال الجارف في بناء الاحداث الدرامية في بنية الصورة لمشاهد الاحلام الفنتازية في الفيلم السينمائي. ثالثاً: مجتمع الأبحث يتمثل مجتمع البحث في الافلام السينمائية التي اعتمدت مشاهد الحلم الفنتازي في

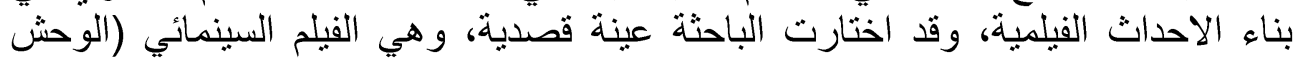
(الذي بنادي). رابعاً: وحدة التحليل اعتمدت الباحثة على اللقطة كوحدة بنائية رئيسة في فيلم (الوحش الذي ينادي). خامساً: عينة البحث البنة بعد ان حددت الباحثة حدود بحثها بالافلام السينمائية التي توظف مشاهد الاحلام

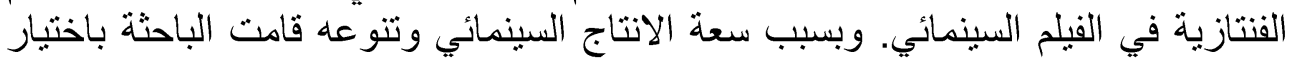

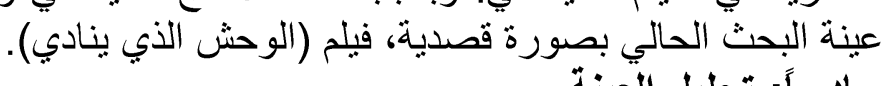
سادساً: تحليل العينة

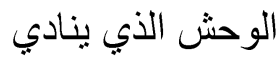

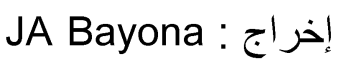
من إنتاج : بيلين أتينز ا، وميتش هورويتس، وجوناثان كينج سيناريو: باتريك نيس البلد : اسبانيا، وأمبركا، وبرئ وبريطانيا سنة الانتاج: 7 البانيان والميركا،

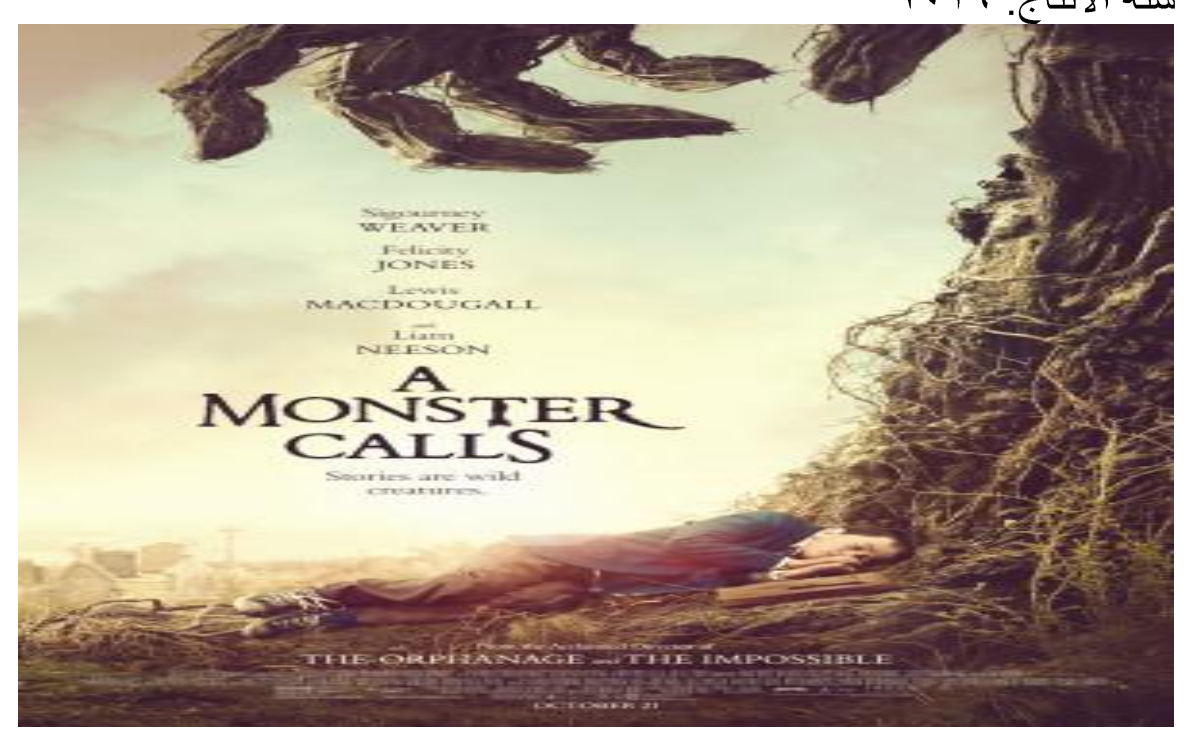




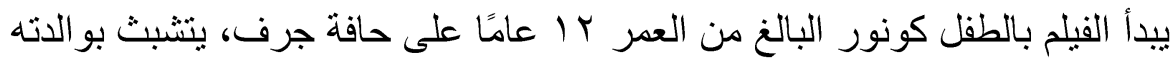

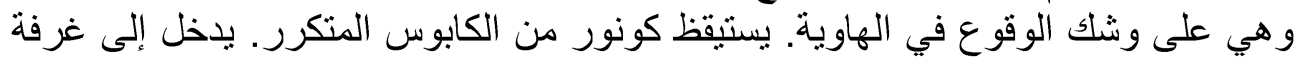

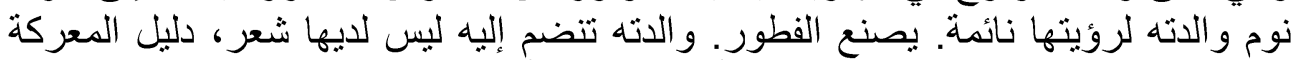

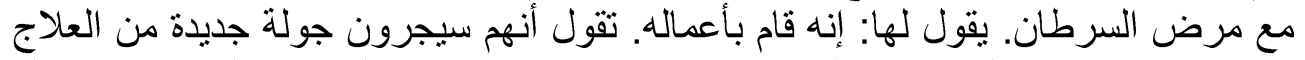

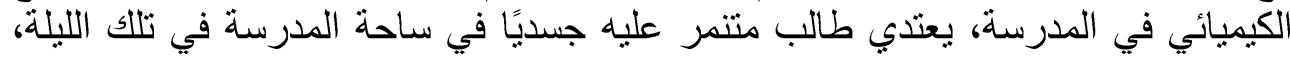

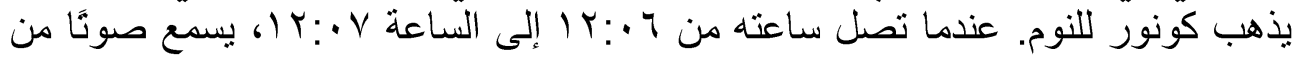

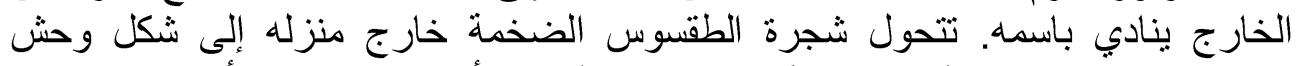

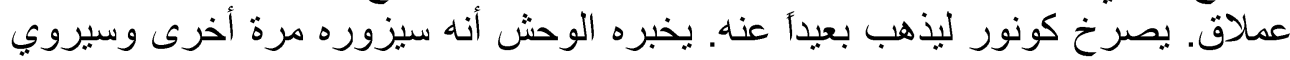

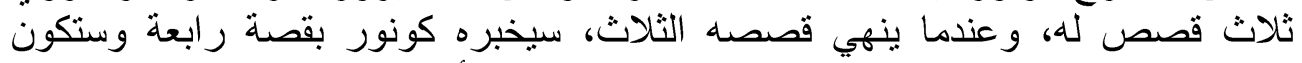

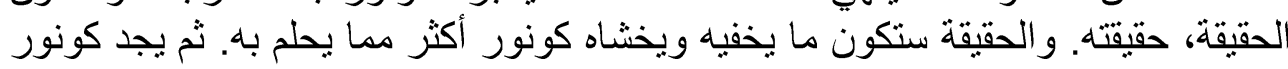

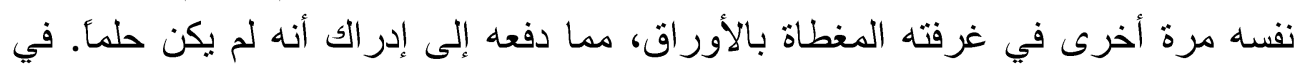

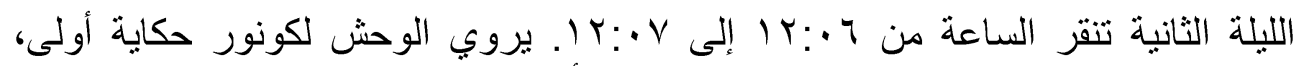

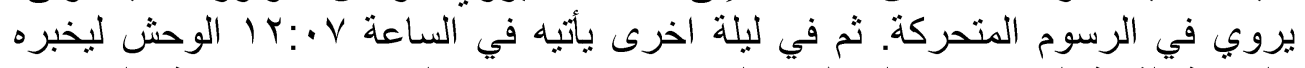

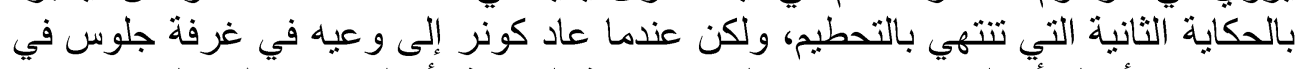

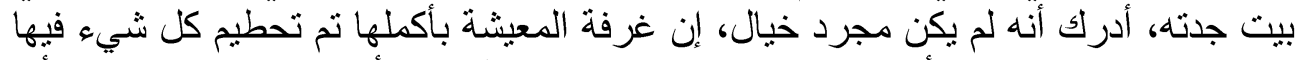

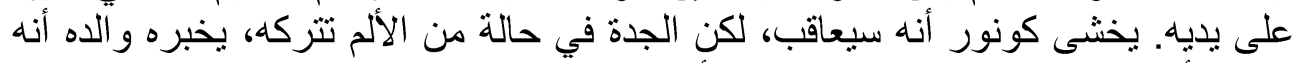

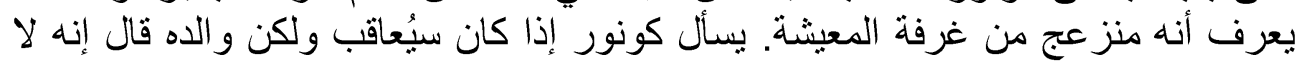

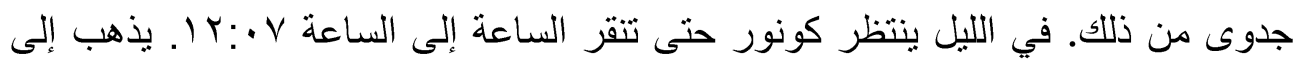

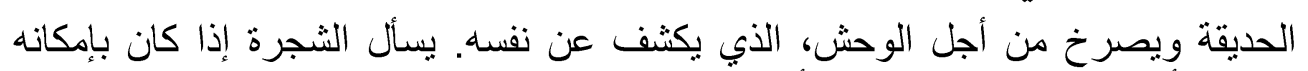

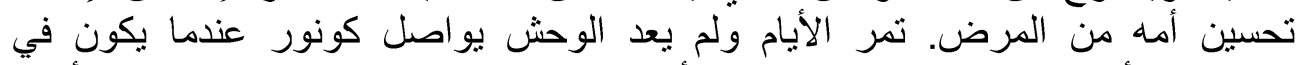

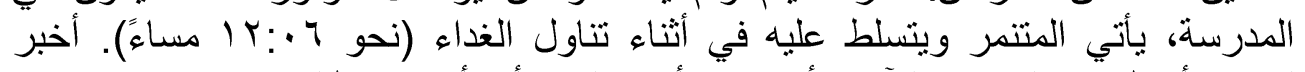

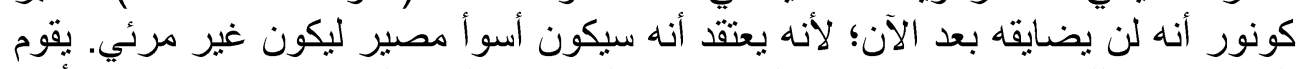

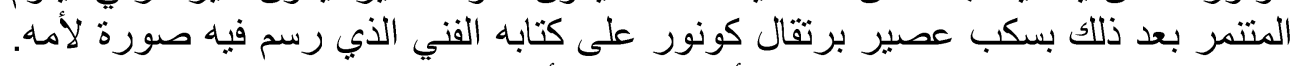

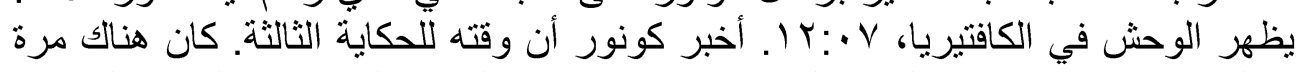

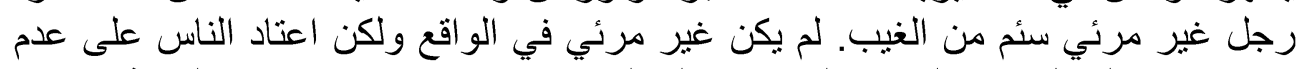

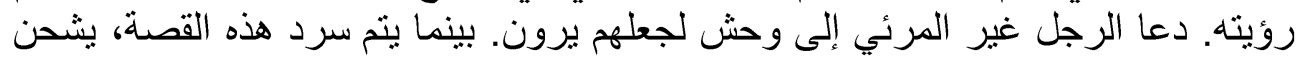

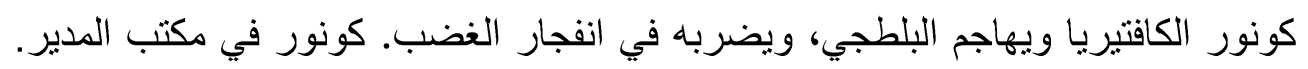

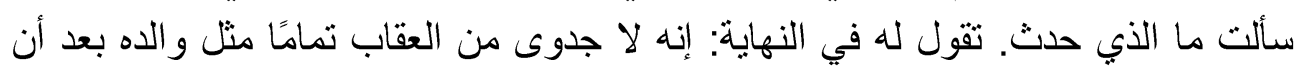

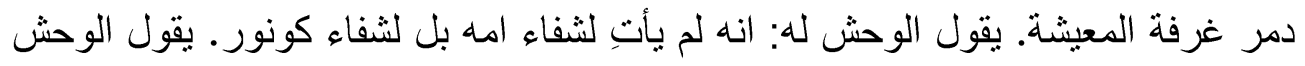

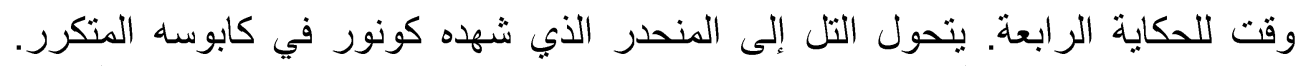

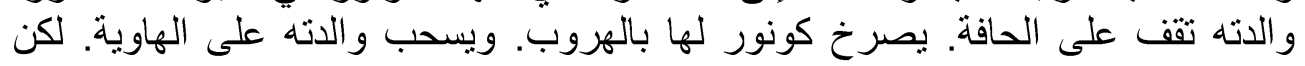

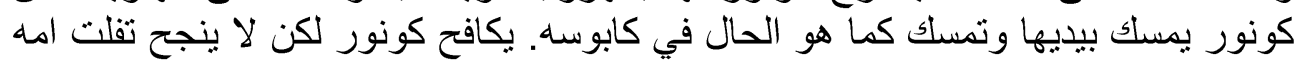

يعتذر كونور عن غرفة المعيشة وتخبره أن ذلك لا يهه، مضيفة أنها ليست الأكثر

$$
\text { وتهوي بالحفرة. }
$$

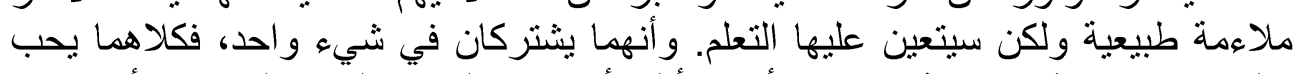

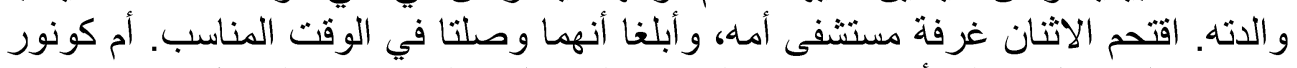

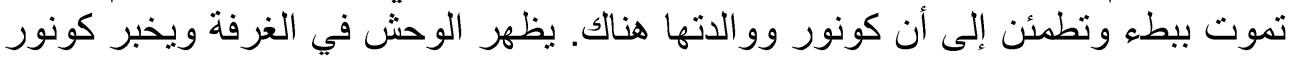




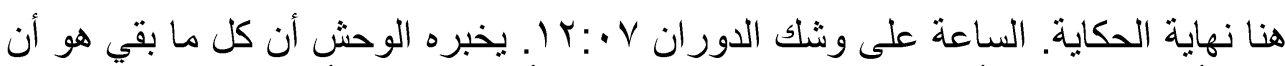

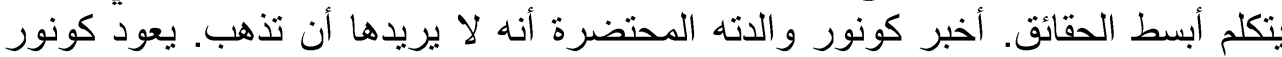

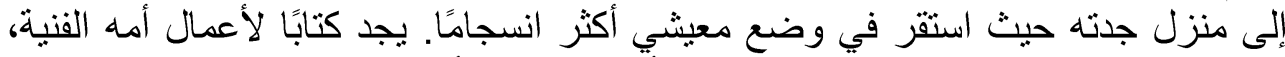

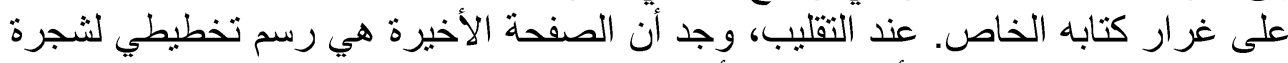

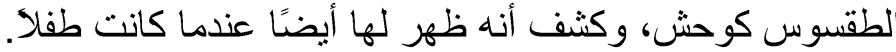

تعتمد السينما الرقمية على الاول التكنولوجيا المعاصرة في بناء البيئات الافتراضية المكونة لمشاهد الاحلام القنتازية في الفيلم السئم السينمائي. يعتمد فيلم الوحش الذي ينادي على التقنيات الرقمية والتكنولوجيا المعاصرة في بناء

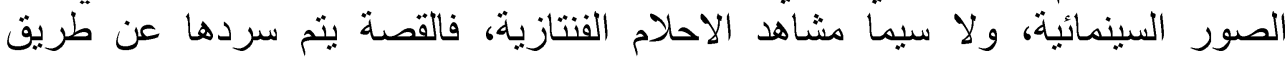

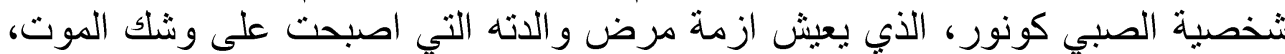

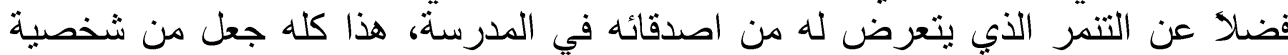
كونور شخصية خبالية، تحاول حل مشكلاتها عن طريق الاحلام الفنتازية، والقوى الخارقة

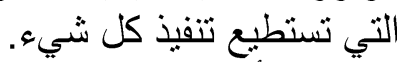
تبدأ احداث الفيلم، بلقطة قريبة للصبي كونور وهو نائم في سريره، يبدو انه يشاهد

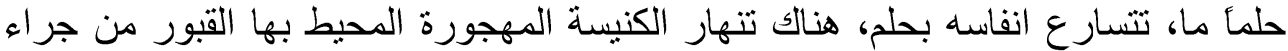

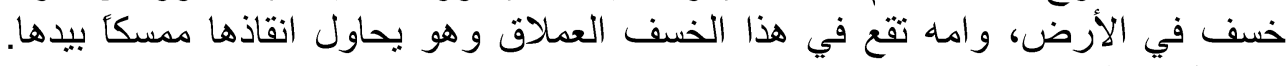

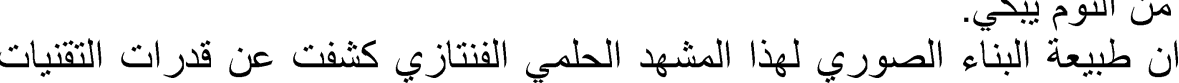
الرقمية في بناء البيئة الافتر اضية بجميع تفصيلاتها وكأنها بنية حقيقية لا يمكن التخيل أبدأ

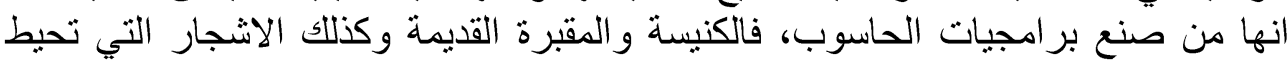
بهذه البنايات كانت غاية في الدقة عند صناعتها داخل بر امجيات الحاسوب الرقاب الرقيةية، هذا

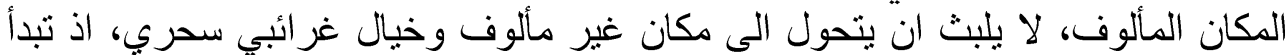

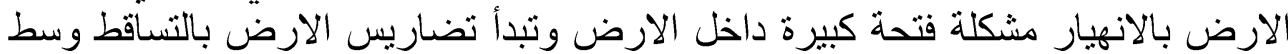

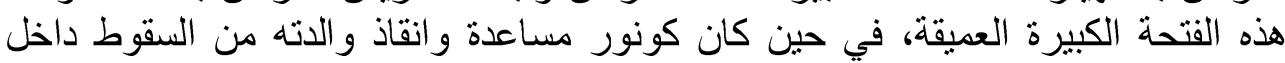

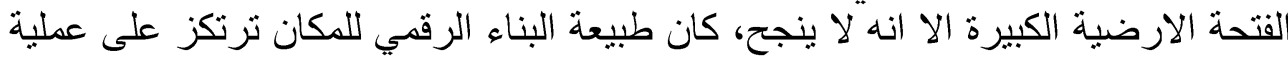

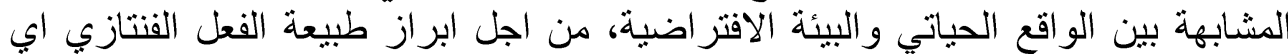

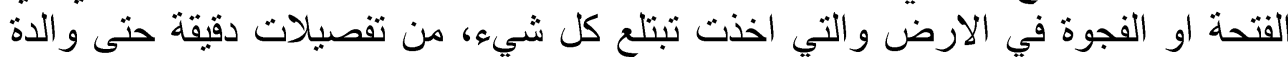

وترى الباحثة ان بر امجيات الحاسوب كانت حاسمة في بناء هذه البيئة الافتر اضية

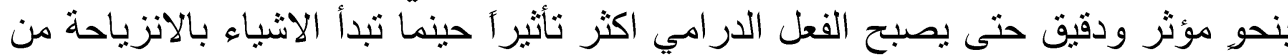
وكانها وتنقط في الفجوة العملافقة.

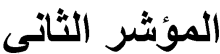
يعد وجود الثخصيات المرقمنة من العناصر الاساسية المشكلة للاحداث الفيلمية لمشاهد الاحلام الفنتازية.

اعتمد فيلم (الوحش الذي بنادي) على بناء شخصية مرقمنة تمثلت في شخصية

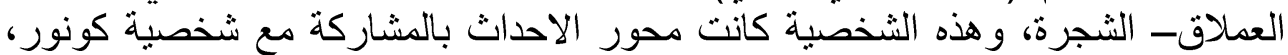

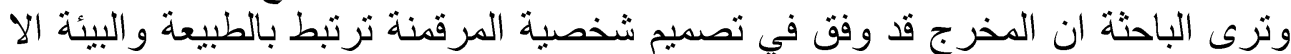

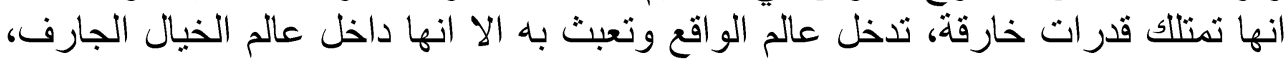


و هذا ما نجح به المخرج في اعتماد العديد من المشاهد على شخصية الوحش الثجرة في

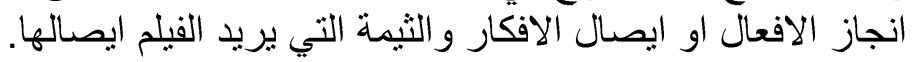

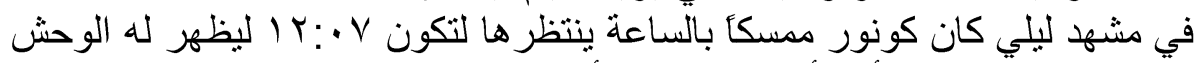

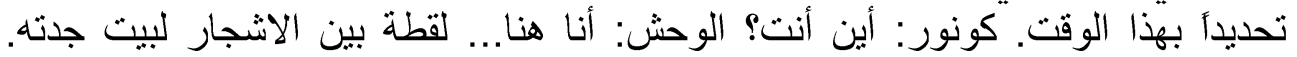

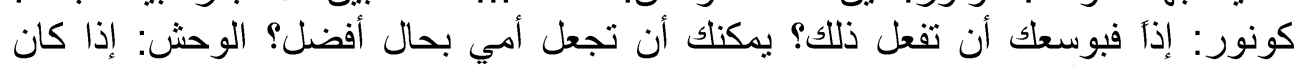

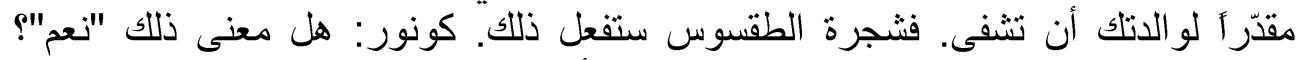

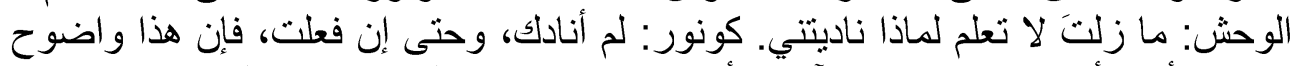

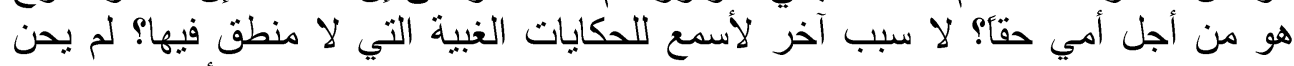

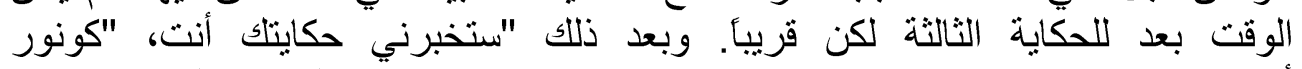

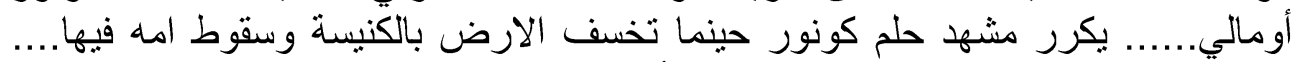

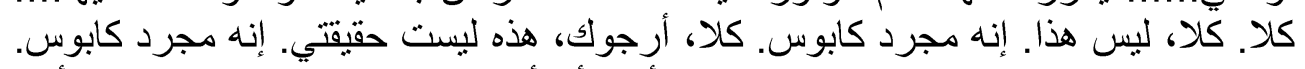

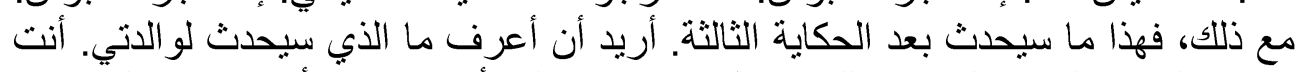

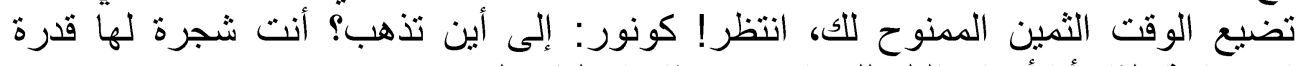

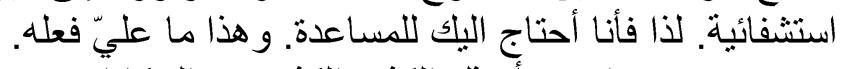

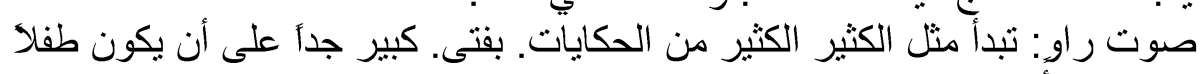

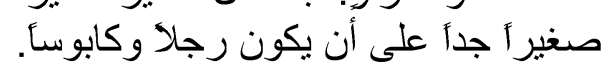

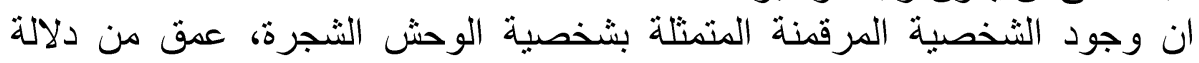

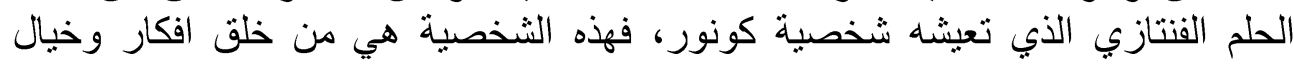

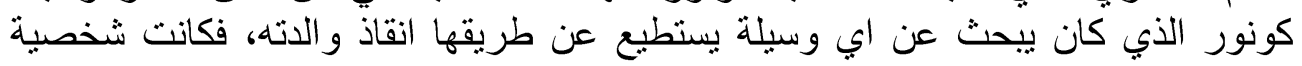

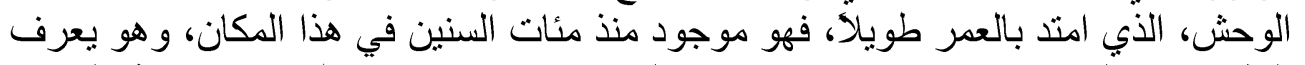

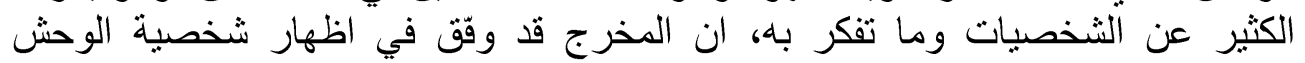

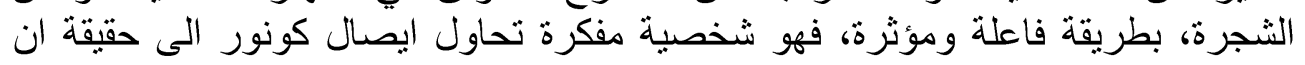

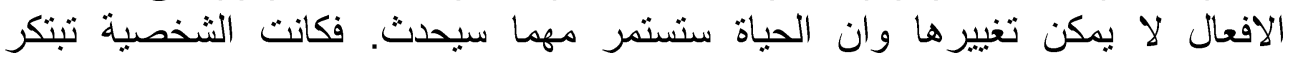

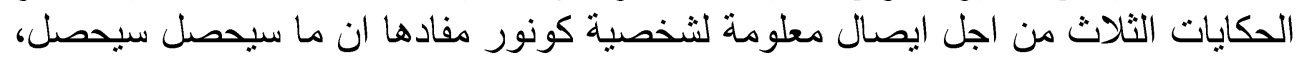

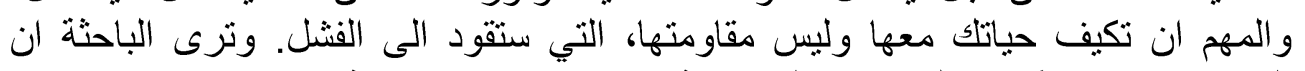

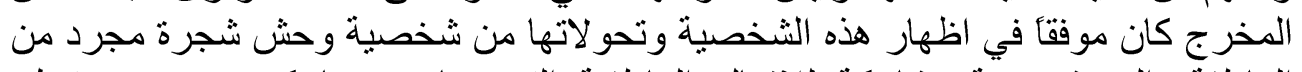

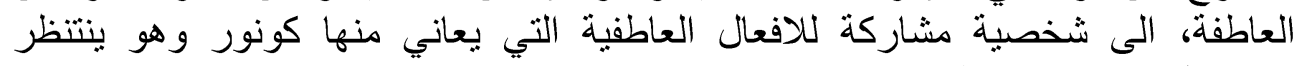

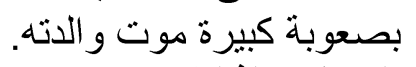

المؤشر الثالث

يتلخل الواقع والخيال الجارف في بناء الاحداث الارامية في بنية الصورة لمشاهد الاحلام القنتازية في الفيلم السينمائي.

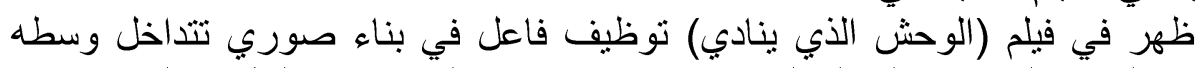

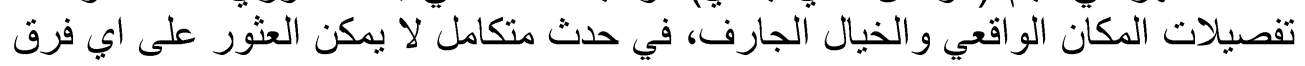

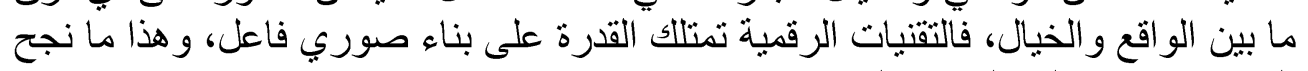

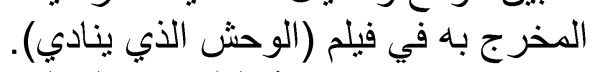

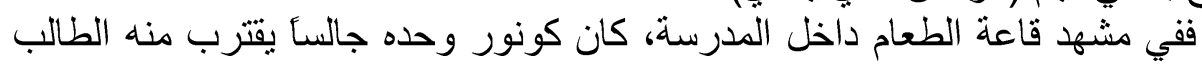

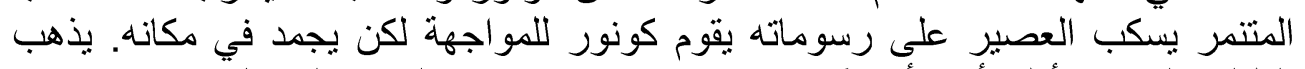

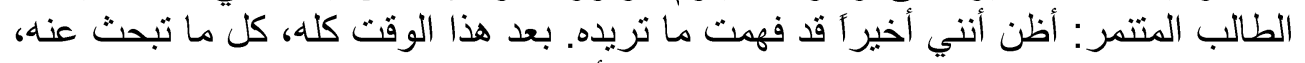

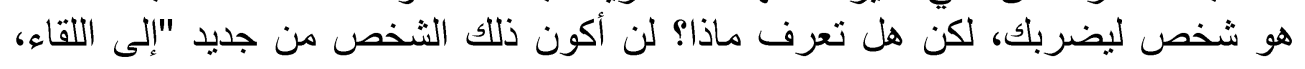




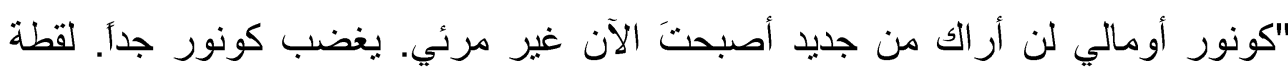

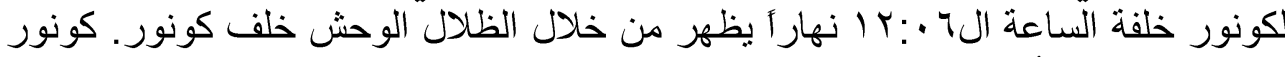

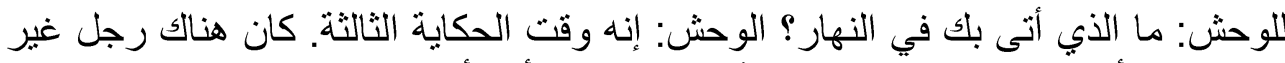

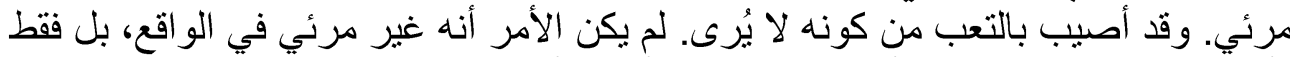

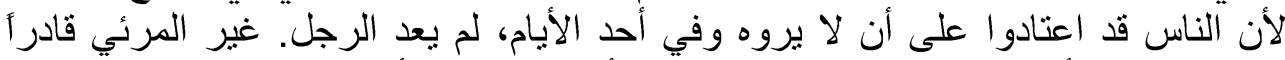

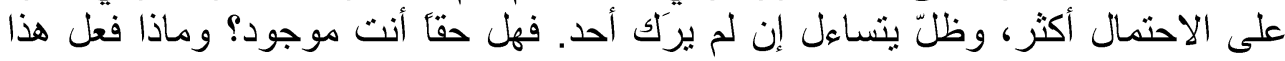

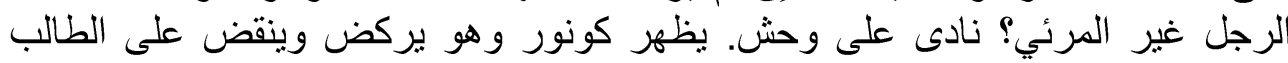
المتتمر و الوحش خلّفة ينفث نار آ وجمراً.

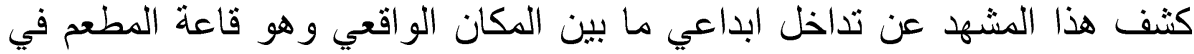

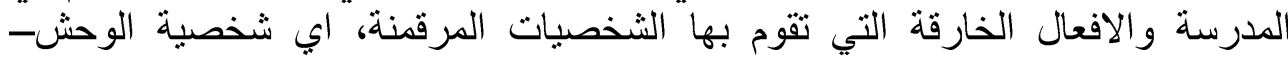

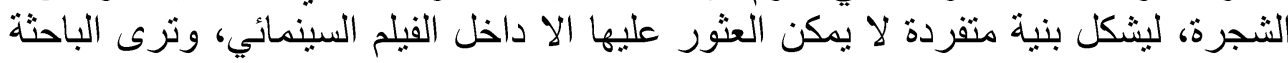

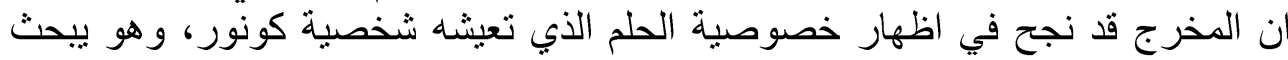

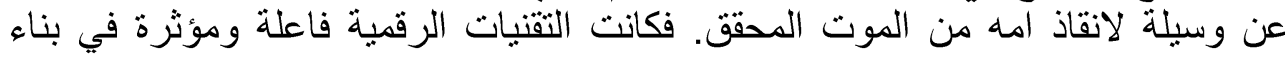

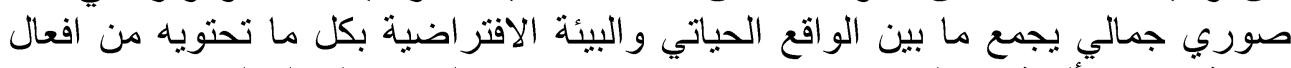

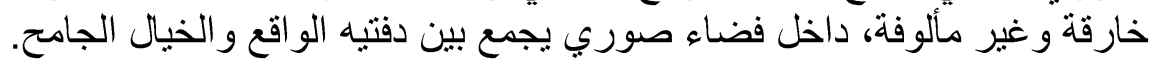




\section{الفصل الرابع: النتائج والاستنتاجات}

أولاً: النتائج

ا. يعتمد البناء الصوري لمشهد الحلم الفنتازي على التقنيات الرقمية في بناء الصورة

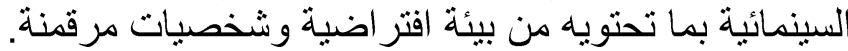

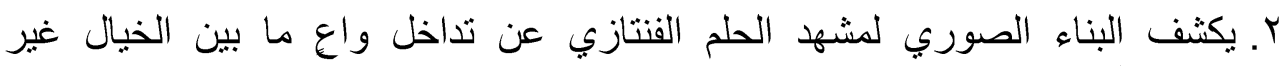
المنضبط و الو اقع الفيزيائي بنحو متكامل. بلن.

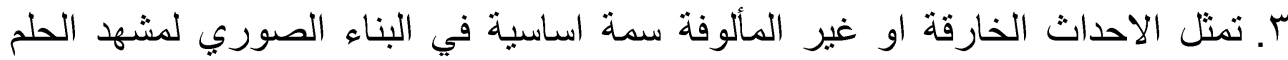

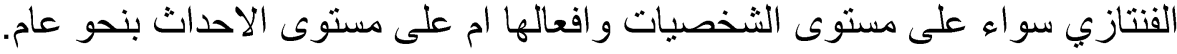

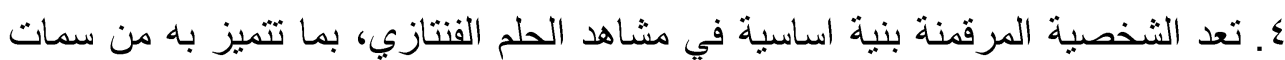
شكلية غر ائبية او افعال لا يمكن للثخصيات الانسة في التسانية القيام بها.

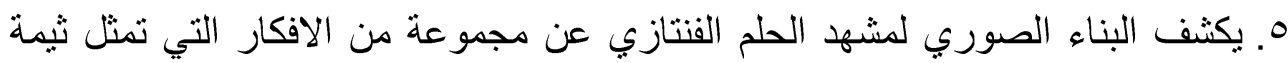

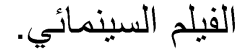

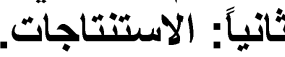

ا ـ مثلت التقنيات الرقمية متغير أ جماليأ في صناعة الصورة السينمائية. r. يمكن صناعة الثخصية المرقمنة بسمات شكلية مختلفة ومغايرة عما هو في في الحياة الهية الفيزيائية.

r. تمنلك التقنيات الرقمية القدرة على تجسيد الافعال الخارقة او غبر المألوفة للثخصيات السينمائية. ع. تعمل البيئة الافتر اضية على بناء وتجسيد صوري لاماكن غرائبية لا بمكن العثور عليها الا داخل عالم الفيلم نفسه.

ه. يكثف البناء الصورة عن تداخل ابداعي ما بين التقنيات الرقمية والتقنيات الكلاسيكية لايصال الاحداث الفيلمية الى المتلقي.

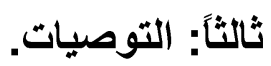

توصي الباحثة بضرورة الاهتمام بالتطبيقات العملية لامكانات التقنيات الرقمية في

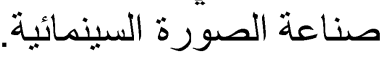

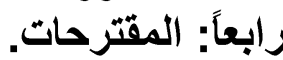

تقترح الباحثة ايجاد دراسة تجمع ما بين الصورة الحلمية والصورة الفيلمية في

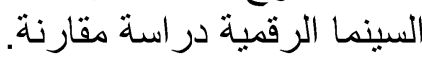




\section{Abstract \\ Graphic Construction of Fantasy Dream Scenes in Digital Cinema By Maha Faisal Ahmed}

Dreams represent a cinematic material par excellence, in which reality and imagination interweave, and it becomes a unique structure with the formations, actions and personalities that go beyond the ordinary, so the dream scenes become a stand-alone structure that aims to convey ideas and information, or what they can carry in terms of predictive values or warning messages or reflect what is simmering in the unconscious character of the dreamer. This topic is what the researcher wanted to study under the title (Graphic Construction of Fantasy Dream Scenes in Digital Cinema), the research depended on the basis of theorizing based on four chapters as follows:

The First Chapter (Methodological Framework): This chapter includes the research problem that is identified by the following question:

How is the graphic construction of fantasy dream scenes done in digital cinema?

Then the researcher identified the importance of the research, as well as the aims and limits of the research.

The Second Chapter (The Theoretical Framework and Previous Studies): The researcher divided the theoretical framework into two sections. The first section is entitled: The Image Structure in the Fantasy Dream Scenes. The researcher dealt with the nature of dreams and, especially dreams of fantasy. As for the second section, it is entitled: Digital Cinema: in which the researcher dealt with the nature of digital cinema, relying on two main elements: the virtual environment and the digitized personality. Then the researcher came out with the indicators of the theoretical framework. The chapter was concluded with previous studies.

The Third Chapter (Research Procedures): includes the research methodology, the research tools, the research population, the unit of analysis and the research sample. Finally, the sample analysis is the movie (The Monster Calls 2016), directed by J.A. Bayona.

The Fourth Chapter (Results and Conclusions): contains the most important results that the researcher came out with from the sample analysis,then the researcher put down some conclusions, recommendations and suggestions, and concluded the research with a list of references that the researcher used in order to complete this research.

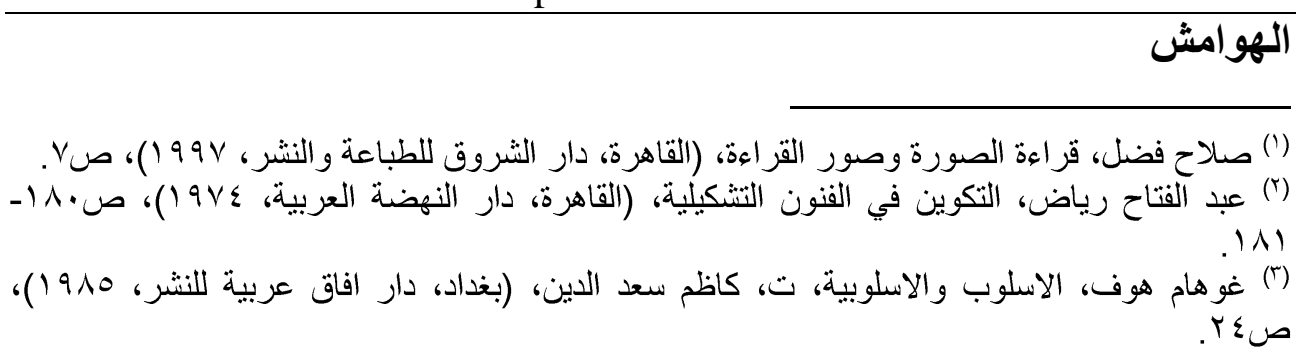


(؛) جيروم ستولنيتز، النقا الفني، ت، فؤاد زكريا، (بيروت، المؤسسة العامة للاراسات والنشر، (919)،

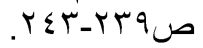

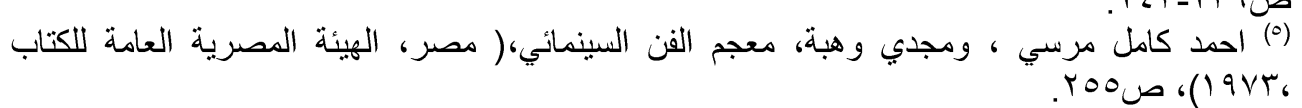

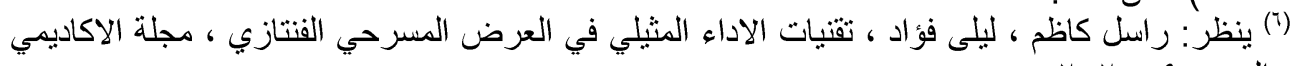

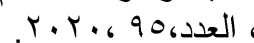

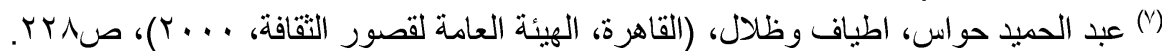

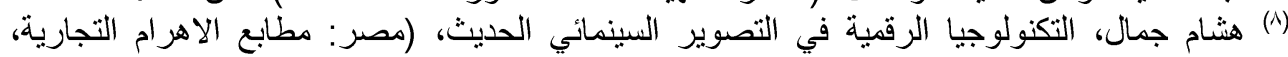

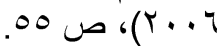

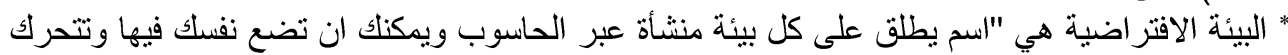

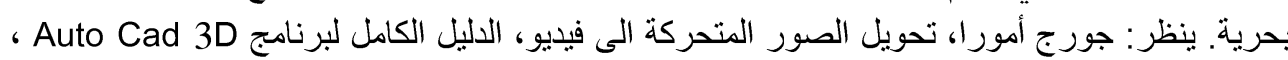

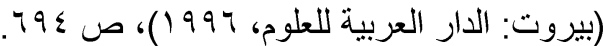

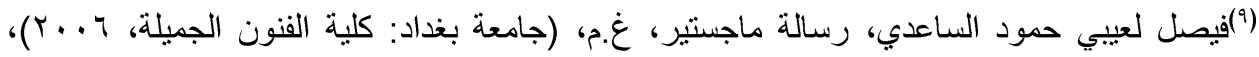

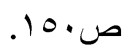

(') (اهاهر مجيد ابراهيم، التتاص الاسطوري في السينما العالمية، (بغداد: دار الشؤون الثقافية العامة،

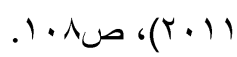

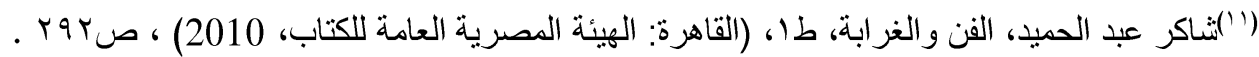

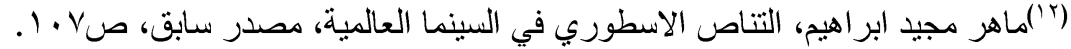

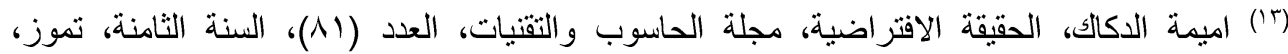

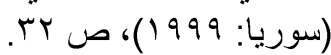

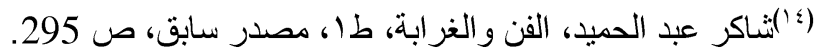

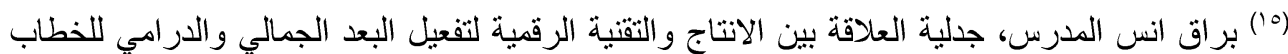

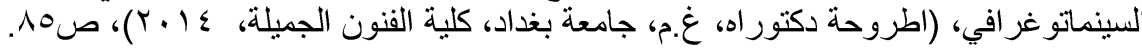

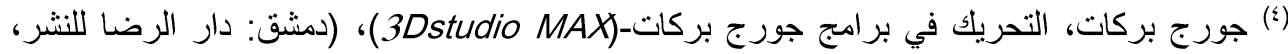

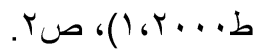

${ }^{(17)}$ Thomas, Ohanian Michael, A. Philips, Digital Filmmaking, $4^{\text {th }}$ ED, London, focal press, 2012,p114.

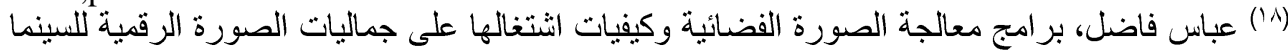

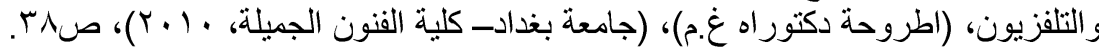
${ }^{(19)}$ bisoft, The Crytek7, chrecter Design \& Proudction, duration 7:02, Frnburu 2013 exhibet, France.

(r.) براق انس المدرس، جدلية العلاقة بين الاتتاج والتقنية الرقمية التفعيل البعد الجمالي والدرامي للخطاب

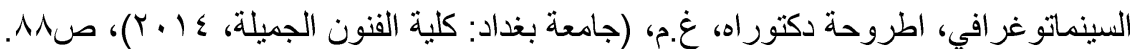

${ }^{(21)}$ Li-juan Wang/Jia-yuan Zhu, Design of New Aerobics Intelligent Motion Capture System, Switzerland, Trans Tech publications, 2013, pp1456.

${ }^{(22)} \mathrm{Li}$-juan Wang/Jia-yuan Zhu, Design of New Aerobics Intelligent Motion Capture System, Switzerland, Trans Tech publications,2013, pp1455.

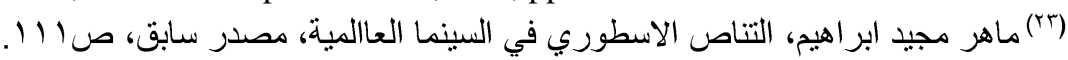




\section{قائمة المصادر}

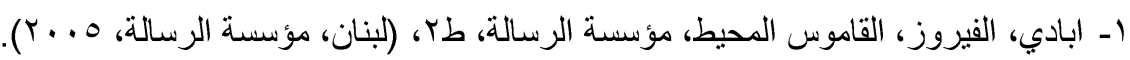

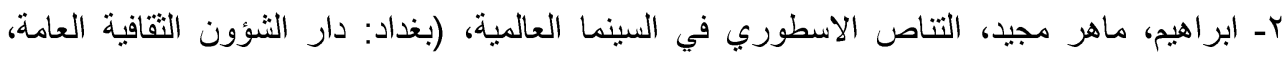

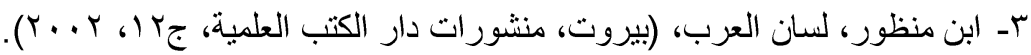

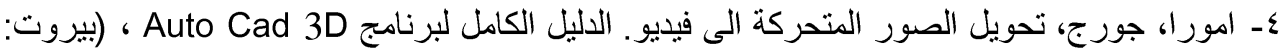

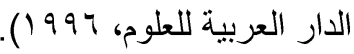

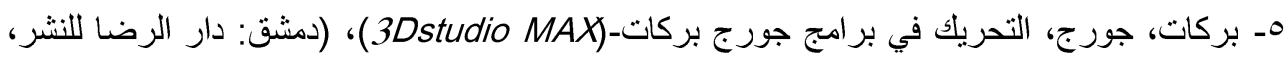
( ( +...

ד- جمال، هشام، التكنولوجيا الرقمية في التصوير السينمائي الحديث، مصر: مطابع الاهرام التجارية، r. . T V- جورنو ماري- تبرينز، معجم المصطلحات السينمائية، ترجمة: فائز بشور، (دمشق: منشورات وزارة

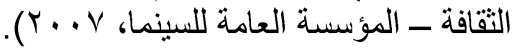

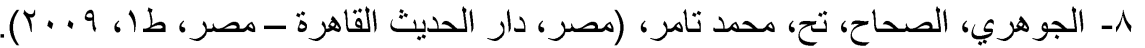

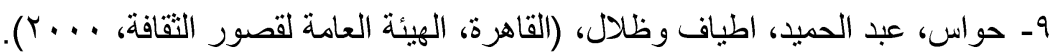

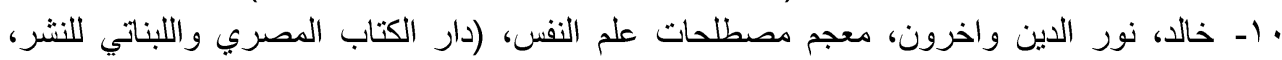
() (1991

1) إلـ الدكاك، اميمة، الحقيقة الافتراضية، مجلة الحاسوب والتقنيات، العدد (1)، السنة الثامنة، سوريا:

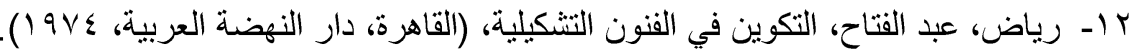

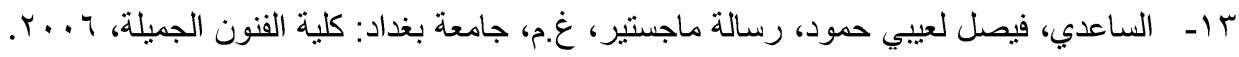
ع ا- ستولنيتز، جيروم، النقا الفني، ت، فؤاد زكريا، (بيروت، المؤسة العامة للاراسات والنشر، (191) ما ـ شرادي، نادية، الحلم تجربة نفسية خاصة، (الجزائر، ديوان المطبوعات الجامعية، بن عكنون، ط، . (T. T

17 إ- عبد الحميذ، شاكر، الفن و الغرابة، طا، (القاهرة، الهيئة المصرية العامة للكتاب، 2010).

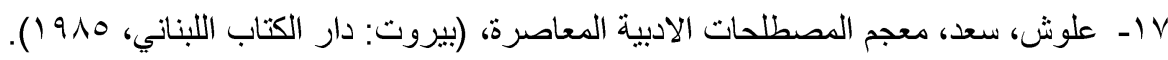

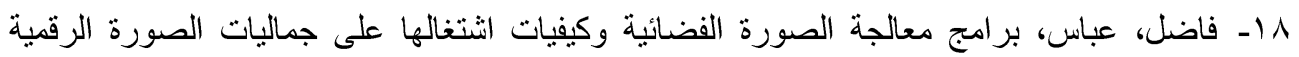

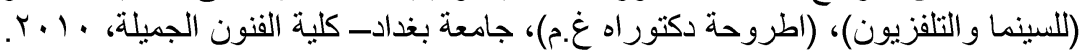

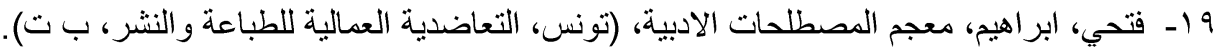

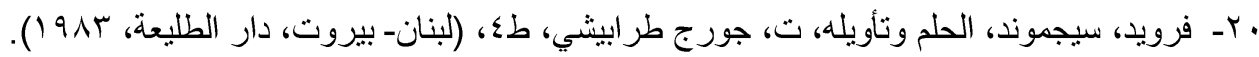

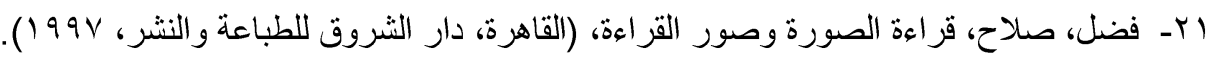

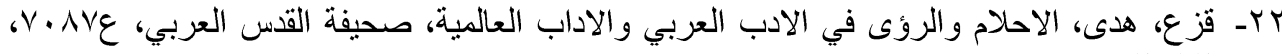
$r+1 r$ rr- كاظم، راسل، فؤاد ليلى، تقنيات الاداء التمتيلي في العرض الدسرحي الفتنازي، مجلة الاكاديمي،

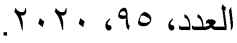

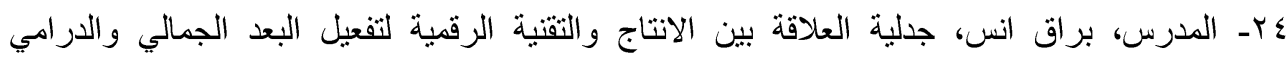

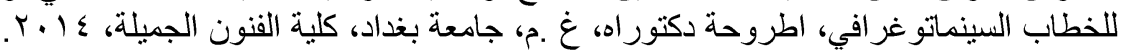

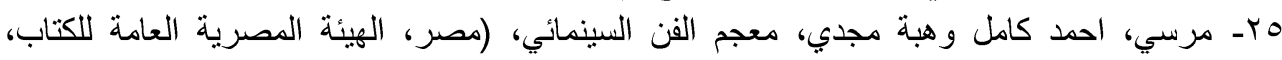




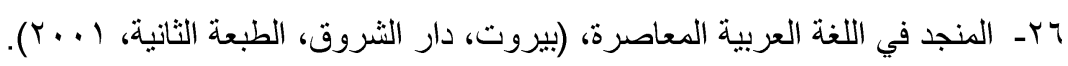

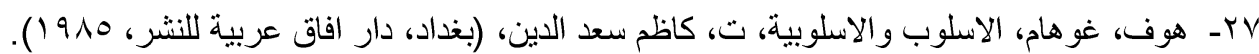
28-Bisoft, The Crytek7, chrecter Design \& Proudction, duration 7:02, Frnburu 2013 exhibet, France.

29-Ohanian, Thomas Michael, A. Philips, Digital Filmmaking, $4^{\text {th }}$ ED, London, focal press, 2012.

30- Oxford, Advonced, Leaner's dictionary, 2000.

31-Wang Li-juan / Jia-yuan Zhu, Design of New Aerobics Intelligent Motion Capture System, Switzerland, Trans Tech publications, 2013. 